\title{
Circadian typology: A comprehensive review
}

Ana Adan ${ }^{1,2}$, Simon N Archer ${ }^{3}$, Maria Paz Hidalgo ${ }^{4,5}$, Lee Di Milia ${ }^{6}$, Vincenzo Natale ${ }^{7}$, and Christoph Randler ${ }^{8}$ *

${ }^{1}$ Department of Psychiatry and Clinical Psychobiology, School of Psychology, University of Barcelona, Spain.

${ }^{2}$ Institute for Brain, Cognition and Behavior (IR3C), Spain.

${ }^{3}$ Faculty of Health \& Medical Sciences, University of Surrey, UK.

${ }^{4}$ Laboratório de Cronobiologia do Hospital de Clinicas de Porto Alegre, Brasil.

${ }^{5}$ Departamento de Psiquiatria, Faculdade de Medicina, Universidade Federal do Rio Grande do Sul, Brasil.

${ }^{6}$ School of Management, Central Queensland University, QLD, Australia.

${ }^{7}$ Department of Psychology, University of Bologna, Italy.

${ }^{8}$ University of Education, Heidelberg, Germany.

* the authors were listed in alphabetical order, except for the corresponding author

Short Running Title: Circadian typology: A comprehensive review

Address correspondence to Ana Adan, $\mathrm{PhD}$, Department of Psychiatry and Clinical Psychobiology, School of Psychology, University of Barcelona, Passeig Vall d'Hebron, 171, 08035 Barcelona- Spain.

e-mail: aadan@ub.edu 


\begin{abstract}
The interest in the systematic study of the circadian typology (CT) is relatively recent and has developed rapidly in the two last decades. All the existing data suggest that this individual difference affects our biological and psychological functioning, not only in health, but also in disease. In the present study, we review the current literature concerning the psychometric properties and validity of CT measures as well as individual, environmental and genetic factors that influence the CT. We present a brief overview of the biological markers that are used to define differences between CT groups (sleep-wake cycle, body temperature, cortisol, and melatonin), and we assess the implications for CT and adjustment to shift work and jet-lag. We also review the differences between $\mathrm{CT}$ in terms of cognitive abilities, personality traits and the incidence of psychiatric disorders. When necessary, we have emphasized the methodological limitations that exist today and suggested some future avenues of work in order to overcome these. This is a new field of interest to professionals in many different areas (research, labor, academic, and clinical) and this review provides a state of the art discussion to allow professionals to integrate chronobiological aspects of human behavior into their daily practice.
\end{abstract}

Keywords: age; circadian typology; chronotype; cognitive performance; morningnesseveningness; personality; psychiatric disorders; sex; shift work. 


\section{INTRODUCTION}

Circadian rhythmic expression differs among individuals and may be classified with the dimension/concept of circadian typology (CT), which consists of three chronotypes (morning-, neither- and evening-type). CT is determined using a number of self-assessment questionnaires that have been validated in several countries. Morning-type (MT) subjects go to bed early and wake up early, and achieve their peak mental and physical performance in the early part of the day. By contrast, evening-type (ET) subjects go to bed and wake up late, and perform at their best toward the end of the day and evening hours. The phase lags in circadian rhythmic functions between extreme groups range from 2 to $12 \mathrm{~h}$, and this has been observed both in biological and behavioral parameters. About $40 \%$ of the adult population is classified in one of the two extreme groups, while $60 \%$ are neither-type (NT).

The interest in the systematic study of the CT is relatively recent and has developed rapidly in the two last decades. All the existing data suggest that this individual difference affects our biological and psychological functioning, not only in health, but also in disease. The epidemiology of CT is influenced by individual factors such as age and sex, which impact on CT across the life-span. Moreover, environmental factors such as the perinatal photoperiod or light exposure also demonstrate an influence on the development of CT. Differences in rhythmic expression between MT and ET can also be found in personality traits, habits and life-styles. Finally, there is little doubt about the association between circadian rhythmicity and psychiatric disorders; most studied are mood and eating disorders, and addictions. There is mounting evidence suggesting the ET typology may be a risk factor linked to chronodisruption aspects, liked to genetic vulnerability and poor life-style choices associated with social jet-lag.

In the present study, we review the current literature in terms of its central findings and offer suggestions to overcome the methodological limitations. In particular, we review the psychometric properties and validity of CT measures as well as individual, environmental and genetic factors that influence the CT. We present a brief overview of the biological markers that are used to define differences between CT groups (sleep-wake cycle, body temperature, cortisol, melatonin), and we assess the implications for CT and adjustment to shift work and jet-lag. We also review the differences between $\mathrm{CT}$ in terms of cognitive abilities, personality traits and the incidence of psychiatric disorders.

\section{MEASURING CIRCADIAN TYPOLOGY}

The publication of the Morningness-Eveningness Questionnaire (MEQ, Horne \& Östberg, 1976), the Diurnal Type Scale (DTS, Torsvall \& Åkerstedt, 1980) and the Circadian Type Questionnaire (CTQ, Folkard et al., 1979) ushered a renaissance to better understand individual differences and 
their role in explaining biological function. These scales can be considered as 'first generation' CT measures and have served as catalysts for the development of several other scales. Subsequent work has been driven by the classical issues that surround measurement (reliability and validity) and the need for shorter measures that can be used in large scale data collection.

\section{Morningness-Eveningness Questionnaire (MEQ) and the reduced Morningess-Eveningness Questionnaire (rMEQ)}

The MEQ (Horne \& Östberg, 1976) is the most widely used morningness measure. Since its publication the MEQ has been cited 1039 times (Scopus, February 2012). The MEQ has 19 items, and the answer options include using a visual analogue scale and choosing between four or five answer options.

The MEQ was administered to 150 adults aged 18-32 and the sample was gender balanced. Forty-eight of these participants were randomly selected and 18 were found to MT and 10 were ET. These participants recorded their oral temperature for three weeks and their sleepwake behaviour. The oral temperature peaked at 19:30 in MT, 20:25 for NT and 20:40 in ET. Hour by hour analysis revealed no significant differences between these groups but large individual differences were observed. MT were found to go to sleep 99 minutes before evening types and woke 114 minutes earlier than evening types but there were no differences in sleep duration. Surprisingly, Horne and Östberg (1976) did not report scale reliability, their justification for dropping three items or the cut-off points to define the CT.

A number of large studies have reported the MEQ to be a reliable measure across several countries. The reliability coefficient has ranged between 0.78 and 0.86 (Adan \& Natale, 2002; Chelminski et al., 1997; Neubauer, 1992) and the stability of the MEQ is strong (0.88 - 0.89) over a three month period (Larsen, 1985; Neubauer, 1992). Validation studies support the distinction between $\mathrm{CT}$ and behaviour. These studies are discussed in the section on cognitive abilities and performance.

The MEQ has received some criticism however. The scale contains 19 items and may be considered lengthy in some situations. A second comment is that the bulk of the variance can be explained by fewer items. Adan and Almirall (1991) found four items had little discriminatory power and Zickar et al. (2002) reported MT items provided the best discrimination. In addition, the MEQ measures a multidimensional construct and, therefore, the use of a total score may not be appropriate.

These criticisms underpinned the development of the rMEQ (Adan \& Almirall, 1991). This scale contains five items and is considered a pure measure of MT. A number of studies have reported the rMEQ and the MEQ to show satisfactory to good correlation $(0.69-0.90)$ and has 
good convergent validity (Adan \& Almirall, 1991; Caci et al., 2009; Chelminski et al., 2000). Natale et al. (2006) reported the rMEQ discriminated MT and ET on the basis of objectively recorded motor activity.

\section{Composite Scale of Morningness (CSM) and the Morning Affect Scale (MA)}

The CSM was developed based on a psychometric assessment of the MEQ, DTS and the CTQ administered to 501 North American students. The CSM consists of the 13 items; nine from the MEQ and four from the DTS (Smith et al., 1989).

Smith et al. (1989) reported scale reliability of 0.87 and international studies have reported similar estimates. Caci et al. (2005a) examined the reliability of the CSM in five countries and estimates ranged between 0.65 and 0.91 . The lowest coefficient was found in Thailand and this may be explained by the fact that several items were modified to reflect local activity timing.

Using self-report data, Smith et al. (1989) found significant differences between CT and bed/wake times, preferred class times and times when students felt at their mental and physical best. These results have been replicated in elsewhere (Caci et al., 1999; Randler, 2009a). Using objective data Guthrie et al. (1995) reported CT differences in sleep behaviour, study time and class performance.

The factor structure for the CSM is less clear (see Di Milia \& Bohle, 2009). However, a brief and reliable 'morning affect' (MA) factor has been identified, and shows good reliability (0.76 - 0.85) in several countries (Caci et al., 2009). The MA scale has been validated against selfreported alertness in a student (Di Milia \& Bohle, 2009) and working sample (Di Milia \& Muller, 2012). Further studies are needed to confirm the utility of the MA scale.

\section{Preferences Scale (PS), Circadian Type Questionnaire (CTQ) and the Munich Chronotype Questionnaire (MCTQ)}

The PS was developed to address several concerns over the CSM (Smith et al., 2002). One problem is the CSM items assume all people work a diurnal schedule. Permanent night- and shift workers may find it difficult to answer how they feel like when they wake in the morning. Second, the varied response formats and the different number of answer choices may combine to increase measurement error (Zickar et al., 2002) and third, the reference to fixed time points does not allow for cultural differences in activity timing (Pornpitkapan, 1998).

The PS addresses these criticisms by using a scale that does not make reference to time of day. Instead participants rate their preference relative to 'most people' on a five-point scale. Across six countries, Smith et al. (2002) reported reliability coefficients between 0.80 and 0.90 . The PS has demonstrated good convergent validity with the CSM (.69- .83) and 0.82 with the 
MEQ (Osland et al., 2011). In terms of construct validity, the literature reports significant differences in sleep/wake timing and alertness by time of day (Bohle et al., 2001; Smith et al., 2002). Di Milia (2005) was unable to replicate the posited PS factor structure but developed a six-item measure that was replicated in a student and working sample.

The focus of the CTQ is to assess the amplitude and stability of the circadian rhythms (Folkard et al., 1979). The underlying hypotheses - "better adjustment might be shown by people with; (a) low amplitude rhythms, and (b) flexible or non-stable rhythms" (p. 80). The measurement properties of the CTQ were poor (Smith et al., 1989) but the rCTI (Di Milia et al. 2004) appears a more promising measure. The rCTI has been replicated in a working sample, scale reliability is good and has shown construct validity; vigorous types were significantly more alert across the day and flexible types were significantly more alert in the evening (Di Milia et al., 2005).

The MCTQ is the most recent CT instrument measure. Roenneberg et al. (2003) argue that assessing CT requires information regarding genetic predisposition, specific timing of sleep onset and offset by work or free days, and light exposure; information not collected by existing measures. The MCTQ determines CT according to the mid-point of sleep (onset and offset) calculated on days off (MSF). Weekend sleep takes into account the fact that ET accumulate a sleep debt which is repaid on weekends (Roenneberg et al., 2007). The mid-point is considered the best indicator of melatonin onset (Terman et al., 2001).

\section{Methodological limitations}

Most of the effort has been directed at improving the reliability of CT instruments but the same rigor has not been applied to scale validation. We summarise the main methodological limitations so that future studies may provide better quality findings.

There appear to be no studies that have employed a representative sample (Caci et al., 2005a). The MCTQ has a large database and may be considered representative but it is a selfselected sample rather than one that is randomly drawn. A second limitation is many studies are gender biased and rely on young student samples. These sample characteristics limit the ability of CT scales to generalise to worker samples. A third limitation is a reliance on cross-sectional studies collecting self-reported data. Studies that collect the dependent and independent variables at the same time may inflate the risk of common method variance. Future studies should employ a split design methodology that results in the collection of independent and dependent data at different time points (Willis et al., 2008). Di Mila et al. $(2008,2012)$ have shown that selfreported data are not necessarily biased but obtaining some objective data is recommended. Fourth, too few studies have assessed the predictive value of $\mathrm{CT}$ in operational settings over the 
longer term (Kaliterna et al., 1995). Fifth, the literature has not explored the inter-relationship between the various circadian rhythm parameters, and perhaps a weighted combination of them may better explain adjustment in night workers (Smith et al., 1989). Finally, from an operational perspective, an unresolved problem is defining the cut-off criteria to identify extreme CT.

\section{INDIVIDUAL AND ENVIRONMENTAL INFLUENCES}

There is evidence suggesting CT is influenced by individual factors, such as age and sex, as well as several environmental factors including the photoperiod at birth, the altitude / latitude of residence, and the subjects' exposure to light.

\section{Age}

After the end of adolescence, morningness scores tend to increase with age (Kim et al., 2010; Merikanto et al., 2012; Monk et al., 2002; Monk \& Kupher, 2000; Paine et al., 2006; Park et al., 2002, Taillard et al., 2004; Tonetti et al., 2008). The age-related shift to morningness is observed after controlling for demographic and socioeconomic factors, and correlates with most of the circadian functions with biological and behavioral circadian parameters (Klei et al., 2005; Monk et al., 2004; Mongrain et al., 2004; Taillard et al., 2011; Zimmermann, 2011). As subjects grow older, there is a tendency to go to bed and wake up earlier, and to present the highest levels of activation at an earlier time, and even more so from the age of 50 on.

Adolescence (12 - 17 years) is a critical period when a shift in $\mathrm{CT}$ is seen to occur from MT to a more pronounced tendency to ET (Achari \& Pati, 2007; Borisenkov et al., 2010; Kim et al., 2002; Randler, 2008a, 2011; Roenneberg et al., 2004; Russo et al., 2007; Tonetti et al., 2008). Eveningness increases from 12 to 15-20 years before a shift to MT becomes apparent. Eveningness may be considered as a biological marker for the end of adolescence (Randler, 2011; Roenneberg et al., 2004). In women, the peak of maximum eveningness appears earlier (Randler, 2011; Tonetti et al., 2008). This phenomenon may be interpreted as associated with pubertal development (Hagenauer et al., 2009), but it is also clearly influenced by social and family factors, such as the school year or parental control on the subject's schedule (Gau \& Soon, 2003; Randler et al., 2009). It is precisely at these ages that the development of an extreme ET should be controlled, since otherwise it could favour an individual functioning with fewer healthy habits and it could also interfere in the adaptation to the socio-environmental demands of the activity (Besoluk et al., 2011; Taylor et al., 2011).

\section{Sex}


The possibility that sex is related to CT has been approached in several studies. Many studies report a larger proportion of ET is found among males, while MT is more commonly observed among females (Adan \& Natale, 2002; Borisenkov et al., 2012; Natale \& Di Milia, 2011; Randler, 2011; Roenneberg et al., 2004; Tonetti et al., 2011). These results tend to be found in large samples that have used the MEQ. However, some studies have not found any gender differences (Paine et al., 2006; Zimmermann, 2011), and others reported ET was higher in females (Merikanto et al., 2012).

The difference in favour of MT in adult women is in accordance with the empirical observation that the diurnal variations in women produce a phase advance with respect to men (Adan \& Sánchez-Turet, 2001; Park et al., 2002), with the magnitude depending on the considered parameter. Moreover, the intrinsic circadian period was significantly shorter in women than in men and a significantly greater proportion of women have intrinsic periods shorter than 24 h (Duffy et al., 2011). This difference can be explained by the control of the circamensual rhythmicity associated with the menstrual cycle in women, which would act against the intensity of the rhythmic control of circadian periodicity (Adan \& Natale, 2002). This argument is supported by the fact that sex differences on CT disappear following menopause in women (Roenneberg et al., 2004; Tonetti et al., 2008). Although there are fewer data available, adolescent samples also find more ET and a delay of sleep timing in boys compared to girls (Borisenkov et al., 2010, 2012; Tonetti et al., 2008).

\section{Photoperiod at birth, longitude and altitude}

With respect to the influence of the photoperiod to which the individual is exposed during the first months of life, the circadian organization of the subjects born with a short photoperiod (autumnwinter) tends to be more MT, while for those with a long photoperiod (spring-summer) it tends to be more ET (Mongrain et al., 2006; Natale \& Adan, 1999; Natale et al., 2002; Natale \& Di Milia, 2011). This is also observed in adolescent samples (Tonetti et al., 2011; Borisenkov et al., 2012), and is more clearly seen in boys or men than in girls or women.

However, studies with Asians participants do not find differences between adolescents and adults (Achari \& Pati, 2007; Harada et al., 2011; Takao et al., 2009), and even the prevalence of sex is the opposite (Gaina et al., 2006). This might be due to biological differences (genetic and ocular photosensitivity) with respect to Caucasians (Tonetti et al., 2011). Taking into account the effect of the photoperiod in the endogenous rhythmic expression, it should be advised that children born in autumn / winter be exposed to light (natural or artificial) despite the weather conditions, while preventing those born in the spring / summer from having an excess of light exposure (Adan et al., 2008). 
The longitude and latitude of residence is also a relevant factor in CT. The CT appears to be associated with the geographical coordinates (east-west and north-south) and in urban areas compared to rural areas both in adults and adolescents (Borisenkov et al., 2010, 2012; Natale \& Di Milia, 2011; Randler, 2008a). Broadly, there are more MT toward the East and North and in rural municipalities.

Finally, in the same place of residence, ET obtained lower levels of light exposure during the daytime and higher during the nightime, together with a more indoor pattern and irregular lifestyle than MT (Gaina et al., 2011; Harada et al., 2011; Martin et al., 2012; Vollmer et al., 2012). With this, there is a decrease in the strength of the light/dark zeitgeber, possibly related to some alterations and disorders, which are commented in the psychiatric disorder section of this review.

\section{BIOLOGICAL DIFFERENCES}

Circadian rhythmicity can be identified in a number of biological markers. These markers include the sleep-wake cycle, body temperature, and the hormones melatonin and cortisol. In this section we will focus on these as well as genetic-based evidence.

\section{Sleep-wake timing}

Sleep is a widespread biological process that is known to have underlying beneficial functions. Sleep is a complex phenotype but has some well-defined characteristics that show high levels of inheritance (e.g. Andretic et al., 2008). An inevitable consequence of any inherited, trait-like characteristic is that it will show inter-individual variation in related phenotypic parameters measured within a population due to associated inherited genetic variation, and this is true for sleep-wake timing and duration (Groeger et al., 2004; Roenneberg et al., 2007).

In humans, periods of sleep and wake are determined by the interaction between a homeostatic process that counts the build-up of sleep pressure during wakefulness and its dissipation during sleep, and the intrinsic circadian clock that produces an oscillatory wakepromoting signal, which has its peak just before sleep and its nadir shortly before wake (Borbely, 1982). The importance of the circadian oscillator in this interaction is well understood because desynchronisation of the two processes is associated with sleep disruption during shift work (Akerstedt, 2003), jet lag (Jamieson et al., 2001), and in free-running blind people (Leger et al., 1999).

It has been shown that the measurement of CT by diurnal preference questionnaires is directly correlated with an individual's intrinsic circadian rhythms. In the development of the MEQ, Horne and Östberg reported an earlier peak of temperature in MT (Horne \& Östberg, 1976). This has been confirmed in subsequent, well-controlled forced desynchrony studies, which 
showed that morningness is associated with a shorter intrinsic circadian period (Duffy et al., 2001; Hasan et al., 2012), as well as an earlier core body temperature phase and earlier wake times (Duffy et al., 2001).

Because of the interaction between sleep and circadian systems and the correlation between circadian rhythms and CT, it should be expected that inter-individual variability in CT would be associated with differences in sleep-wake timing. Indeed, a consistent finding from studies that have measured $\mathrm{CT}$ in humans is that there is a strong association between $\mathrm{CT}$ and sleep-wake timing, such that MT wake up and go to bed earlier than ET (Horne \& Östberg, 1976; Robilliard et al., 2002; Taillard et al., 2004). In addition, it has also been reported that differences in $\mathrm{CT}$ are associated with differences in the regulation of sleep homeostasis as measured by the EEG, such that MT have a higher percentage of stage 1 sleep, more spectral power in the sigma range during NREM sleep (an indicator of cortical arousal), and a faster decay of NREM slow wave activity (Mongrain et al., 2005, 2006). These altered characteristics of sleep homeostasis point toward a higher rate of sleep dissipation in MT that may also represent an underlying homeostatic contribution to sleep-wake timing differences between MT and ET.

It should be noted, however, that the relationships between CT, circadian rhythms, and sleep-wake timing are more complex and also change with age. In young MT, there is an earlier circadian phase (of melatonin and core body temperature) compared to ET, but the interval between the circadian phase and wake time is longer in MT than in ET (Duffy et al., 1999). This means that whereas ET wake up at a later clock time, MT wake up at a later circadian phase. However, this relationship changes with age, such that older MT have an earlier phase than young MT, but also a shorter interval between circadian phase and wake time (Duffy et al., 1999). This means that older MT are more similar to younger ET in this respect. With age the increase in morning preference and earlier wake times is accompanied by age-related changes in sleep capacity, such that older people have reduced baseline daytime sleep propensity and shorter durations of sleep in laboratory conditions, compared to younger people (Klerman \& Dijk, 2008). These age-related findings again emphasise the important interactions between sleep and circadian processes in the determination of $\mathrm{CT}$.

Several investigations have found no overall association between CT and sleep duration (e.g. Horne \& Östberg, 1976; Robilliard et al., 2002). However, one on-going survey of CT using the MCTQ shows clear workday-weekend differences in sleep duration, but also demonstrates an interesting relationship between sleep duration and sleep timing (Roenneberg et al., 2007). Consistent with previous studies, the data show no evidence for an overall correlation between sleep duration and sleep timing, with short $(\leq 6 \mathrm{~h})$ and long $(\geq 9 \mathrm{~h})$ sleepers having equal CT distributions, suggesting that these two traits are independent. However, the data nicely show the 
distinct effects of work, with a negative correlation between $\mathrm{CT}$ and sleep duration during workdays (late types sleep for less), and a positive correlation at weekends (late types sleep for longer). Thus, CT differences in sleep debt accumulated during workdays can affect sleep duration and timing.

Finally, the contribution of external, social factors to CT should not be underestimated. Because the two processes of circadian rhythms and sleep homeostasis interact so precisely to determine sleep/wake timing, desynchronization of the two can lead to metabolic and cardiovascular problems and also circadian rhythm sleep disorders, such as shift work disorder and delayed sleep phase disorder (Luyster et al., 2012; Sack et al., 2007). Social factors can lead to this desynchronization during normal working lives. ET who go to bed late but rise early because of work times or family commitments will wake up at a time that is out of synch with their circadian clock and also accumulate a sleep debt during the week. This 'social jetlag' is common in our current society and has been shown to be associated with metabolic disorders and depression (Wittmann et al., 2006; Levandovski et al., 2011; Roenneberg et al., 2012). Thus, there needs to be careful consideration of $\mathrm{CT}$ and work schedules and how these interact to determine health outcomes.

\section{Body temperature}

Several studies have shown that MT have an earlier circadian temperature phase than ET measured both by rectal (Duffy et al., 1999) and oral temperature (Gupta \& Pati, 1994). This phase difference is around two hours both in normal day-night conditions (Baehr et al., 2000) and during a constant routine (Kerkhof \& Van Dongen, 1996).

This circadian phase difference is explained by endogenous factors and not by differences in sleep schedules. In normal day-night conditions the phase angle, defined as the interval between the trough of the body temperature and wake up time, is shorter in ET compared to MT. However, these differences tend to disappear in experimental conditions (Mongrain et al., 2004). Therefore, it is possible conclude that social demands have a large impact on when people wake up in relation to their circadian clock, inducing the disadvantages this may cause to ET.

Because women tend both to have a longer sleep duration than men (Natale et al., 2009) and an higher predisposition to morningness (Adan \& Natale, 2002), women show a longer phase angle in comparison to men (Mongrain et al., 2004).

ET show a higher amplitude in circadian fluctuation of body temperature in comparison to MT (Baehr et al., 2000). The strength of the human circadian system is thought to be correlated to its amplitude. This could be one reason why ET are considered to have a higher tolerance for shift work than MT. 


\section{Cortisol}

Some studies have focused on the relationship between $\mathrm{CT}$ and the cortisol awakening response. Bailey and Heitkemper, using both salivary cortisol sampling (1991) and plasma cortisol (2001), revealed a higher amount of cortisol in MT in the morning. In healthy, day-active adult men, Kudielka et al. $(2006,2007)$ found an overall effect of CT and salivary cortisol level after awakening. The acrophase of cortisol in serum was 55 minutes earlier in MT (Bailey \& Heitkemper, 2001), while Griefahn and Robens (2008) reported higher cortisol levels in MT after awakening but not during the rest of the day. Randler and Schaal (2010) reported MT had higher cortisol levels immediately after awakening. Dockray and Steptoe (2011) -after different adjustments- found no effect of CT on cortisol in the evening, the cortisol awakening response, or total cortisol output over the working day, whereas on the leisure day, total cortisol output was greater in ET. In another study, ET showed lower salivary cortisol levels and a flattened diurnal curve (Oginska et al., 2010). As these results are somewhat inconclusive, further studies are needed addressing weekend and weekday cortisol awakening response, both measured by spontaneous awakening and by forced waking (alarm clock). Generally, it seems that cortisol may enable people to prepare for the day and the higher cortisol values in MT may explain why MT show a better morning affect, e.g., feel less tired at awakening.

\section{Melatonin}

Melatonin is considered as a physiological cue for the organism and its onset has been described as the best predictor for sleep onset (Arendt, 2006; Rosenwasser, 2009). Moreover, the melatonin rhythm is argued to be the best marker of the endogenous circadian pacemaker (Benloucif et al., 2005). The onset, acrophase, and offset of the melatonin profiles occurred approximately 3 hours earlier in MT than in ET, without differences in amplitude (Gibertini et al., 1999; Griefhan et al., 2002; Mongrain et al., 2004, 2005). This was observed both in blood and in salivary measurements. In a study with records during extended wakefulness, an advance was also observed in the time of salivary melatonin peak and dim-light melatonin onset in the MT with respect to the ET, although without differences in the area under the curve (Taillard et al., 2011). There is an inverse relationship between MEQ scores and the time of the melatonin peak (Liu, 2000).

The maintenance of the melatonin circadian rhythm is considered as a biological marker associated with successful ageing, while the flattening of the rhythm is related to the appearance of neurodegenerative diseases and the concomitant presence of psychiatric pathology (Magri et al., 2005; Wu et al., 2005). 
A new physiological parameter has recently been proposed for assigning the $\mathrm{CT}$, based on daily secretion patterns of melatonin and growth hormone (Nagane et al., 2011). The results suggest that the asynchronicity and lack of peak secretion at midnight for the two hormones reflect ET. This new parameter correlates with psychosomatic complaints but requires further validation studies.

\section{Genetic basis}

We have already seen how circadian and sleep systems interact to determine CT. Circadian rhythms are generated by a core set of circadian clock genes and proteins that interact in a transcriptional/translational feedback loop to determine circadian period (Ko \& Takahashi, 2006). Less is known about genes underlying sleep regulation, but it is becoming increasingly evident that several clock genes also have roles in sleep regulation and homeostasis, which is consistent with the known interaction between the two systems (for review, see Franken \& Dijk, 2009). As previously mentioned, some characteristics of sleep are highly heritable, but twin studies have also shown that CT has a very high overall heritability of around 50\% (Koskenvuo et al., 2007; Barclay et al., 2010). Therefore, because circadian and sleep systems interact to determine CT, it should be expected that variation in genes that have roles within these systems will be associated with individual differences in CT phenotypes.

By far the most successful approach to date in identifying genetic polymorphisms that are linked with differences in CT has been via the candidate gene approach, driven by systematic screens of clock gene polymorphisms. This approach has identified a catalogue of polymorphisms in clock genes that show associations with CT phenotype, including CLOCK (Katzenberg et al., 1998; Mishima et al., 2005), PER1 (Carpen et al., 2006), PER2 (Carpen et al., 2005), and PER3 (Archer et al., 2003, 2010; Johansson et al., 2003; Jones et al., 2007; Pereira et al., 2005; Lazar et al., 2012). However, several studies have failed to replicate some of these associations in alternative populations: CLOCK (Barclay et al., 2011; Chang et al., 2011; Johansson et al., 2003; Pedrazzoli et al., 2007), PER3 (Barclay et al., 2011; Osland et al., 2011). The reasons for the failure to replicate these findings are unclear, but may be related to differences in phenotyping methods, ethnicity differences, age and sex differences, sample size, geographic location, and even time of year of study. A good example of how age can be a confounding factor in these CT genotype/phenotype associations, which can be relatively weak, comes from a study that showed different levels of significance among different age groups for a polymorphism within PER3 (Jones et al., 2007). The association is strongest for younger people and gradually reduces with age until it becomes absent in middle-aged people between 40 and 49 years old. Interestingly, this 
is also the age where females no longer report greater morningness scores than males of the same age in the MCTQ data (Roenneberg et al., 2007).

In all of the above examples of associations between $\mathrm{CT}$ and clock gene polymorphisms, it is not known what the underlying biochemical or physiological mechanisms are that lead to the phenotypic differences. However, some of the same polymorphisms have also been linked with delayed sleep phase disorder (DSPD), in which sleep onset and offset are delayed late into the night and day (CLOCK - Mishima et al., 2005; PER3 - Ebisawa et al., 2001; Archer et al., 2003, 2005; Pereira et al., 2005). For PER3, these polymorphisms are hypothesised to affect the promoter-driven gene expression levels of PER3 (Archer et al., 2010), or are hypothesised to alter the phosphorylation state of the PER3 protein by removal of potential Casein Kinase I (CKI) phosphorylation sites (Archer et al., 2003; Ebisawa et al., 2001). The latter is important because studies have shown that changes to the phosphorylation levels of PER protein can change circadian period (Lee et al., 2011). In addition, familial mutations in PER2 (Toh et al., 2001) and $C K I$ (Xu et al., 2005) have been linked with advanced sleep phase disorder (ASPD) where it has been shown that greatly advanced circadian rhythms and sleep timing are due to changes in phosphorylation of PER protein.

Although genetic associations with $\mathrm{CT}$ are not always reproducible, so far the association that has been reproduced most often is with the variable number tandem repeat (VNTR) polymorphism in PER3. This primate-specific (Jenkins et al., 2005), coding-region polymorphism in humans gives rise to four or five repeated 18-amino-acid motifs that contain multiple, putative CKI phosphorylation sites (Archer et al., 2003). Because CKI phosphorylation of PER was known to be an important determinant of circadian period and linked with ASPD, it was hypothesised that the PER3 VNTR polymorphism would be associated with differences in CT in humans (Archer et al., 2003). This was indeed the case, such that morning types were more likely to be homozygous for the 5-repeat allele $\left(P E R 3^{5 / 5}\right)$ and evening types and also people with DSPD showing greater frequencies of PER $3^{4 / 4}$ homozygotes (Archer et al., 2003; Jones et al., 2007). The same association has been replicated in a Brazilian study (Pereira et al., 2005) and more recently in a separate UK-based study (Lazar et al., 2012). Whereas previous studies had only genotyped subjects with extreme CT phenotypes, the latter study investigated the association in 675 subjects who were not selected on the basis of their CT phenotype but nevertheless found that increased morning preference was associated with the $P E R 3^{5 / 5}$ genotype. As part of a large battery of screening questionnaires, the study employed both the MEQ and the MCTQ tools, in addition to questionnaires and diaries to record sleep timing. This approach enabled contrasts to be made between workdays and rest days and revealed novel genotype associations that were dependent on this contrast. $P E R 3^{5 / 5}$ subjects went to bed earlier, had an earlier mid-point of sleep and woke up 
earlier than the other genotypes. $P E R 3^{5 / 5}$ had a shorter 'time in bed' during workdays than $P E R 3^{4 / 4}$ but there was a significant interaction between genotype and workdays versus rest days such that $P E R 3^{5 / 5}$ actually spent the longest time in bed during rest days. Interesting correlations were also observed with body mass index (BMI), such that if the midpoint of sleep was later than 04:15 during workdays, $P E R 3^{5 / 5}$ individuals had a significantly higher BMI than the other genotypes, and if time in bed was greater than 9 hours during workdays, they also had a lower intelligence score. These observations underline the importance of taking into account differences between workdays and rest days, as previously emphasised for other MCTQ data (Roenneberg et al., 2007).

While it was assumed that the PER3 VNTR would exert its influence on CT via the circadian clock, this no longer seems likely. Multiple human studies (Archer et al., 2008; Hasan et al., 2012; Viola et al., 2007) have shown no evidence for circadian differences between PER3 genotypes, although a recent study in older people does report a phase advance in melatonin in $P E R 3^{5 / 5}$ subjects compared to $P E R^{4 / 4}$ (Viola et al., 2011). The influence of the PER3 VNTR on CT appears to be more closely linked with mechanisms that regulate sleep timing and homeostasis. $P E R 3^{5 / 5}$ people have earlier sleep/wake times (Lazar et al., 2012) and show increased EEG theta activity during wakefulness and greater slow wave activity power during NREM sleep, both markers of greater homeostatic sleep pressure (for review, see Dijk \& Archer, 2009). PER $3^{5 / 5}$ people also show a greater cognitive decline in response to sleep deprivation (Groeger et al., 2008). A model can now be envisaged whereby greater sleep pressure in the $P E R 3^{5 / 5}$ modulates diurnal variation in performance and alertness via feedback onto the circadian wake-promoting signal, leading to a preference for morning activity in these people. This model also fits well with what we know about the important interaction between sleep and circadian systems and emphasises the point that $\mathrm{CT}$ is a complex phenotype that is derived from multiple underlying genetic factors.

\section{ADJUSTEMENT TO SHIFT WORK AND JET LAG}

One intended purpose of CT scales is to identify individuals that may better adjust to night work. However, the literature linking $\mathrm{CT}$ and adjustment is indicative of a relationship but is far from convincing, while the relationship with jet lag is even more problematic. In this section we review evidence for the validity of these measures to predict adjustment in shift work and jet lag.

The major limitations include the absence of representative samples, few longitudinal designs, the absence of control groups and a reliance on self-reported data. A recent review of this literature identified 16 studies; all these were cross-sectional and only two collected objective data (Saksvik et al., 2010). Furthermore, our review of these studies revealed that six studies used a 
single-item measure to assess CT, five used different versions of the CTQ/I, four used the CSM, one study used the MEQ, and another used five items from the MEQ.

Seo et al. (2000) administered the MEQ to 561 shift workers across a number of heavy industries. MT found the night shift more difficult. This group reported significantly more sleepiness during the night shift, were more likely to nap and the naps were of a longer duration. Khaleque (1999) studied 60 male shift workers and the results suggested ET had less sleep interruption during day sleep compared to MT. Small, large and epidemiological studies each report an association between ET and night work (Adan \& Almirall, 1991; Paine et al., 2006; Petru et al., 2005).

Several studies report on the CSM and its relationship with night work adjustment. McLaughlin et al. (2008) reported morningness was a moderate predictor of tolerance to shift work. Older individuals were more likely to be MT and reported greater difficulties concerning sleep, fatigue and negative affect. Willis et al. (2008) found ET had significantly greater workfamily conflict but no differences were found for burnout, depersonalisation and accomplishment. In a large-scale study of nurses and industrial workers, morningness did not predict sleep or social/domestic disturbance (Smith et al., 1999). Di Milia and Muller (2012) showed that MT shift workers were significantly more alert during the morning hours but this pattern changed in the evening/night hours when ET were more alert.

The CTQ and rCTI are also supported as predictors of adjustment to shiftwork. Smith et al. (1999) reported that irrespective of the actual shift schedule parameters and type of job, workers with inflexible sleeping habits had greater sleep disturbances and in turn resulted in increased fatigue and emotional disturbances. Furnham and Hughes (1999) found journalists with flexible sleeping habits were better able to overcome drowsiness and had greater well-being. In addition, they also reported night journalists to be ET. Vela-Bueno et al. (2010) investigated adjustment in 265 aircraft technicians. Their results indicated the 'non-adapted' workers were morning oriented, had rigid sleeping habits and were languid. In a rare study, Kaliterna et al. (1995) collected individual differences data from workers before commencing shift work and at a three-year follow up. Workers with rigid sleep habits and languid behaviour were more likely to report poor health, psychosomatic and digestive complaints. It is important to note these correlations were small but nevertheless significant.

The rCTI (Di Milia et al., 2005) is being used in a series of longitudinal studies and results from the first wave of data collection are now available. Natvik et al. (2011) reported on the survey responses from 1,500 nurses working either two or three shifts. After controlling for demographic factors, rigidity was associated with insomnia among the three shift workers and languidity was associated with greater sleepiness, depression and anxiety. In a group of 
experienced nurses, Saksvik et al. (2012) found flexibility but not languidity was positively linked with shift work tolerance.

The DTS (Torsvall \& Åkerstedt, 1980) reported strong correlations between morningness and a number of sleep complaints. MT reported less sleep problems during the day shift while ET reported more problems. This pattern was reversed during night work. Natvik et al. (2011) found morningness was negatively related with insomnia. Morningness by shift type was significant overall for depressive symptoms and morningness was associated with lower depressive symptoms in three-shift workers. Saksvik et al. (2012) reported morningness predicted adjustment to night work among inexperienced nurses. This finding is unexpected but this group was younger and had worked less than 20 night shifts across the year.

We found one published study (Gamble et al., 2011) using a modified version of the MCTQ in a nursing sample. Night shift nurses had a significantly later chronotype than day nurses. The interaction between shift type and CT suggested the earlier types had better adaptation to day work but worst adaptation on night shift. By contrast, the late CT had intermediate adaptation to both shifts. We located a doctoral study (Juda, 2010) that discusses the development of the MCTQ ${ }^{\mathrm{SHIFT}}$ that applies a series of corrections according to the shift being worked. The results are interesting and require replication in larger samples.

Jet lag refers to the misalignment between the internal clock and external time cues (Arendt, 2009). Thus, in many ways jet lag sufferers and shift workers report similar impaired characteristics with the exception that shift workers internal clocks are disrupted on a more frequent basis. There is a good deal of literature advising travellers on how to minimise jet lag (Eastman \& Burgess, 2009). There is speculation that better adjustment may be found in people with flexible sleeping habits and that MT would find it easier to cope with eastward travel, while ET cope better with westward flights (Waterhouse et al., 2007). However, the study of CT and jet lag is notable for the absence of studies.

Waterhouse and his colleagues (2002) studied 85 athletes, coaches and academics on a flight from London to Sydney. Participants completed the CSM, CTI and several other measures. The findings suggested flexible types were able to go to sleep earlier and stay asleep for the first night only and no effect was found for rigidity of sleeping habits. Morningness failed to predict tolerance to jet lag but this may be explained because 78 participants were intermediate types.

Flower et al. (2003) surveyed 100 participants that had flown across five time zones at least once in the previous six months. After adjusting for gender, the evidence was weak but suggested flexible sleeping habits was associated with less travel fatigue but that morningness was not a significant predictor. Finally, in a review of circadian rhythm sleep disorders Sack et al. (2007) concluded: "no study has examined the utility of the MEQ in assessing risk for the 
development of" jet lag disorder (p. 1474). Future studies need to employ better designs before the link between $\mathrm{CT}$ and jet lag can be outlined.

\section{COGNITIVE ABILITES AND PERFORMANCE}

In spite of the work carried out in the past decades (Adan et al., 2008; Cavallera et al., 2011; Guerrien et al., 1993), it is still difficult to synthesize the relationship between CT and cognitive performance because of the great number of variables considered, and the heterogeneity of the research methods adopted.

In this section we aim to attract the reader's attention towards the possible explicative role of $\mathrm{CT}$ in the comprehension of cognitive functioning in humans. First we focus on methodological issues, and then we comment the role of $\mathrm{CT}$ in relation to time of day effect and to individual differences framework.

\section{Methodological issues}

To remove the masking effect and dissect the contribution of circadian and homeostatic influences on performance rhythms, specific study protocols have been developed: constant routine protocol (CR); CR with multiple naps; forced desynchrony protocol (FD) (Blatter \& Cajohcen, 2007). However, these experimental protocols set human participants in artificial conditions questioning the applicability of the results to every day life (Vanin et al., 2012).

We suggest that circadian fluctuation data of cognitive performance may be recorded and evaluated in normal day-night condition with greater accuracy if CT is taken into account. The biological and behavioral parameters studied in connection to the $\mathrm{CT}$ are now numerous. As for body temperature (the gold standard parameter for the circadian clock), it is known that both extreme types reach the acrophase in the second half of the day, even if, the MT reach it around 2 hours earlier than ET (Kerkhof \& van Dongen, 1996). On the contrary, for both subjective and objective alertness, daytime trends seem almost specular (Natale \& Cicogna, 1996). The MT reach the acrophase in the first half of the day, whereas the ET reach it in the late afternoon. Therefore, CT could be considered as a paradigm offered by the nature in which circadian pacemaker and homeostatic processes are differently mixing and/or interacting. Bearing in mind that a CT-based protocol cannot permit to segregate the respective contributions of circadian and homeostatic processes, it nevertheless has the advantages being very ecologic and gives realistic indications about human behavior in normal day-night conditions (Valdez et al., 2008).

Monk and Leng (1986) found a greater phase difference in a logic reasoning task than in a visual search task in the extreme CT. On the basis of this evidence, they posited that the nature of the task, and hence the resource required to carry it out, might be critical in differentiating the 
performance diurnal trend in the CT. In particular, they suggested that tasks involving large amounts of cognitive resources would better differentiate the two extreme CT, since these tasks are not simply mediated by changes in arousal levels but also by changes in performance strategy. Interpreting the results from complex task performance introduces a new question: which is the cognitive function giving the prevalent contribution to solve the task? Moreover, time of day effects depend not only on the task complexity but also on the way in which it is performed. Indeed, researchers suggest that many time of day effects do not reflect automatic changes arising from processing limitation, but are due to the adoption of different strategies over the course of the day (Folkard, 1990). It is not clear whether the strategy changes observed over the day reflect endogenous rhythms or are attempts to maintain competent performance in a sub-optimal state. The mobilization of effort in a task is also modulated by the demands of the task itself. The roles of endogenous rhythms, exogenous factors and motivation have been separately studied, but we have to keep in mind that it is the combination of these factors and the individual's interpretation of them which determines the nature of the observed time of day effect on performance in normal day-night conditions as well as in everyday life (Smith, 1992; Adan, 1993; Clarisse et al., 2010).

\section{Time of day and cognitive performance}

The interest in time of day effects on cognitive efficiency has a long history (Laird, 1925). Kleitman (1963) showed strong evidence for a parallelism between body temperature (the gold standard mark of the human circadian system) and time of day effects for simple repetitive tasks: the decrease in reaction time response was significantly correlated to an increase in body temperature. These data become known as the arousal model (Colquhoun, 1971). In this model, circadian performance variations are postulated to reflect an underlying circadian rhythm in basal arousal level. Because body temperature increases during the day, also the performance efficiency should always increase during the day. Both extreme CT reach a higher arousal level in the second half of the day, and thus for both extreme CT the arousal model foresees better cognitive performances in the second half of the day. However, in a study in which a simple weak motor component task was scheduled every 2 hours from 8 am to $10 \mathrm{pm}$, it was found that ET improved their performance during the day, whereas MT presented an opposite trend, with a phase advance up to 12 hours (Horne et al., 1980). As far as memory tasks are concerned, some studies have shown a phase advance of the best performance time ranging between 2 and 6 hours for MT (Adan, 1991; Anderson et al., 1991; Natale \& Lorenzetti, 1997; Petros et al., 1990).

Homeostatic processes are also involved in the modulation of cognitive efficiency. During a normal day the most important effect is the so-called post-lunch impairment which has been found both in real life jobs and in the laboratory. Lavie and Segal (1989), using the ultrashort 
sleep-wake paradigm, reported a much clearer post-lunch dip in MT than for ET. The post-lunch dip could be modulated by blood concentrations of naturally occurring benzodiazepine, which reach relative higher values at noon in MT in comparison to ET (Sand et al., 2001).

It is unlikely that cognitive efficiency is solely mediated by circadian (body temperature) or homeostatic (sleep-wake cycle) processes. From a behavioral point of view, alertness derives from the interaction of these two processes (Natale \& Cicogna, 1996). Therefore, to explain so large a phase difference in cognitive efficiency between MT and ET, the role of alertness was then considered, which is a behavioral and not physiological variable. It was concluded that cognitive performances are more efficient when testing time is in synchrony with individuals' peak in alertness. This model is known as the synchrony effect (May \& Hasher, 1998), and states that individuals who are more alert in the morning tend to perform better in the morning than in the afternoon, and individuals who are more alert in the evening tend to perform better in the afternoon or evening than in the morning. Data supporting the synchrony effect were collected adopting a range of cognitive tasks, including negative priming, false memory, recognition and recall of prose and span materials, categorization, judgment and control over distraction, and working memory (Intons-Peterson et al., 1998, 1999; May, 1999; Hasher et al., 2002; Yang et al., 2007; Rowe et al., 2009; Hornik \& Miniero, 2009).

However, the synchrony effect did not globally affect performance. In fact, synchrony effect was not documented in a constant way for all studies (Ciarkowska, 1997; Fabbri et al., in press; Gilloly et al., 1990; Natale et al., 2003). In a recent study examining the effect of time of day on problem solving, the results seem to indicate that tasks involving creativity might benefit from a non-optimal time of day (Wieth \& Zacks, 2011).

On the basis of results involving $\mathrm{CT}$ as an independent variable, it is possible to conclude that it is over simplistic to link cognitive efficiency only to arousal or alertness. Cognitive efficiency is not solely determined by underlying regulatory activation systems, but it is modulated by compensatory mechanisms, such as motivational factors or expectancy due to experience. It is possible to conclude that in normal day-night conditions, tasks requiring a high operational load could involve a cognitive and motivational engagement that can offset the decrease in efficiency induced by alertness changes. This could explain why tasks involving a wider range of cognitive resources present no relevant differences between the two extreme typologies.

These last observations allow us to introduce the importance for distinguishing among arousal and arousalability, which means that the arousal system can be differentiated into tonic (slow adapting arousal state) and phasic (which rapidly adapts to transient changes) activation. Current models of attention in cognitive science postulate three primary functions for attentional 
mechanisms (i.e., alerting, orienting, and executive control), each of them presumably corresponding to underlying distinct and independent neural networks (Fan et al., 2002). The purpose of the alerting network is to increase and sustain arousal and vigilance in order to better prepare the organism for the detection of forthcoming stimuli (phasic attention). The orienting network specializes in selecting specific information from an array of potentially relevant stimuli. The executive component of attention mediates planning, decision making, error detection, conflict resolution and inhibitory control. The efficiency of the alerting, orienting, and executive components of attention is frequently measured with the Attention Network Test (ANT) (Fan et al., 2002). Only one study used the ANT paradigm in relation to CT (Matchock \& Mordkoff, 2009). The orienting component showed no time of day effect or CT effects, whereas executive control was lower in the middle of the day regardless of CT. By contrast, alerting scores significantly increased in the second half of the day for MT and NT, while results were stable over the day for ET. Results relative to MT are not surprising because a larger alerting effect is associated with a difficulty to maintain alertness without a cue, while results relative to ET are somewhat surprising (Fan \& Posner, 2004). On the whole, these results introduce a last possible question: is $\mathrm{CT}$ associated with differences in cognitive styles regardless of time of day?

\section{Cognitive styles}

It is commonly believed that going to bed early and getting up early would result in better performance across the day. This belief is not supported by empirical data (Gale \& Martyn, 1998). The few studies that have examined this question obtained small but significant correlations in the opposite direction: ET showed higher intelligence scores (Kanazawa \& Perina, 2009; Roberts \& Killonen, 1999; Song \& Stough, 2000). Kilgore and Kilgore (2007) administered the MEQ and Wechsler Abbreviated Scale of Intelligence to 54 healthy volunteers and found a small but significant negative correlation demonstrating the better performance of ET on verbal ability. In a study of adolescents, MT were reported to perform better on final school examination (Randler \& Frech, 2006). However, the authors correctly noted that school start time is early, while adolescents biologically tend to shift towards eveningness at this time (Tonetti et al., 2008). Therefore, ET might be at a disadvantage because they have gone to bed too late and so do not have enough sleep.

A more interesting approach is to consider the cognitive style. Cognitive style is not an ability but a preferred way of information processing. This approach seeks to understand the preferred strategies one adopts rather than performance per se. Three kinds of styles have been found: cognitive styles, learning styles, and thinking styles (Sternberg \& Zhang, 2001). Cognitive styles indicate attitudes and tendencies to activate distinctive mental operations in a variety of 
situations. Thinking styles concern which set of reasoning strategies an individual is inclined to apply. Learning styles characterize how a person faces study tasks. From the perspective of cognitive styles, ET has been associated with field independence (Sarmàny, 1984) and creative thinking (Giampietro \& Cavallera, 2007).

Learning and thinking styles have been related to an individual's hemisphere preference (Spinger \& Deutsch, 1997). Folkard (1990) suggested that diurnal changes in performance may also reflect a change across the day concerning the dominance of the left-hemisphere. Corbera and Grau (1993) studied 48 right-handed women who performed verbal and spatial hemifield tachistoscopic tasks at four different times a day. Changes in accuracy over the day showed a left hemisphere advantage at 12:00 whereas right hemisphere use had an advantage at 19:45. Several studies have also demonstrated a change over the day in hemispheric dominance (Folkard, 1990; Iskra-Golec \& Smith, 2006; Natale et al., 2003; Shub et al. 1997) is a significant factor when we try to understand the heterogeneity between tasks in the literature regarding the time of day effect. Using the Style Of Learning And Thinking questionnaire, Fabbri et al. (2007) showed that MT is associated with the left-thinking style and ET is associated with the right-thinking style. The leftthinker follows an analytic and sequential mode of reasoning and he/she relies preferably on verbal-abstract representation. On the contrary, the right-thinker tends to process information in an intuitive, holistic, gestalt-type, synthesized, and visual-motor way (Torrance et al., 1988).

The concept of hemisphericity is obviously a schematic way to represent the reality, but this concept could allow us to give a summarized description of individual differences. We hope that future research will deeply analyze the relationship between CT and cognitive style suggesting that ET and MT tend to follow different cognitive processes.

\section{PERSONALITY RELATIONSHIPS}

There have been some previous attempts to summarize the relationship between circadian typology and personality (see Tankova et al. 1994: Cavallera \& Guidici, 2008). The early literature focused mainly on Eysenck's three factor model while more recent studies have used different models. The purpose of this section is to first review the EPI literature and then assess the relationship between $\mathrm{CT}$ and more recent personality inventories.

\section{Eysenck Personality Inventory (EPI)}

Studies using the EPI have relied mainly on the extraversion and neuroticism dimensions and less on psychoticism. Some studies have also examined the subcomponents of extraversionimpulsivity and sociability (Eysenck \& Eysenck, 1975). Neuroticism is generally related to 
emotional stability while psychoticism provides a link to detect conduct disorders (Eysenck et al., 1985).

ET typically report higher scores in extraversion than MT (Tankova et al., 1994; Mitchell \& Redman 1993; Langford \& Glendon 2002), while Matthews (1988) reported this relationship only in women and some studies yielded no relationship between CT and extraversion (Tankova et al., 1994; Mecacci \& Rochetti, 1998). However, no studies have found an inverse relationship between ET and extraversion. These results suggest that the relationship between ET and extraversion is the most stable relationship obtained with the EPI. However, it is still unclear which component of the extraversion dimension is responsible for this relationship. As Tankova et al. (1994) point out in their review, some studies found ET had higher scores for sociability and others for impulsivity, while some detected no relationship.

The results for neuroticism show contradictory results. Some have reported higher scores in ET (Tankova et al., 1994; Mecacci \& Rochetti, 1998) while two studies found MT had higher scores (Tankova et al., 1994; Langford \& Glendon, 2002). Several studies reported no relationship between CT and neuroticism (Tankova et al., 1994; Mitchell \& Redman 1993). Studies based on the psychoticism dimension of the EPI suggest ET score higher on this dimension than MT (Mitchell \& Redman 1993; Tankova et al., 1994; Mecacci \& Rochetti 1998), and this may be linked to psychopathology. Differences in results may be related to different samples or study designs.

\section{Big Five Model}

The Big Five Model (or Five Factor Model) is made up of the following factors: extraversion, agreeableness, conscientiousness, neuroticism and openness (Costa \& McCrae, 1992). Extraversion is related to a high degree of sociability, assertiveness, and talkativeness. Agreeableness is characterized by being helpful or cooperative towards others. Conscientiousness refers to being disciplined, organized, and achievement-oriented. Neuroticism refers to emotional stability, and anxiety. Openness means a strong intellectual curiosity and a preference for novelty.

ET were reported to be marginally but not significantly more extroverted than MT (Jackson \& Gerard, 1996). No other study found a relationship between extraversion and CT. There was a positive relationship between agreeableness and morningness (de Young et al., 2007; Hogben et al., 2007; Randler, 2008c), but no relationship between agreeableness and CT could be detected (Gray \& Watson, 2002; Jackson \& Gerard, 1996; Tonetti et al., 2009). In all studies conscientiousness showed a positive relationship to morningness and is considered the best predictor of morningness. In some studies, neuroticism was higher in ET individuals (de Young et al., 2007; Randler, 2008c; Tonetti et al., 2009) but no relationship was found in others (Jackson \& 
Gerard, 1996; Gray \& Watson, 2002; Hogben et al., 2007). ET had a higher openness (Hogben et al., 2007) while no relationship could be detected in five other studies (de Young et al., 2007; Gray \& Watson, 2002; Jackson \& Gerard, 1996; Randler, 2008c; Tonetti et al., 2009).

\section{Temperament and Character Inventory (TCI)}

The TCI has a theoretical psychobiological basis (Cloninger, 1994). These include four dimensions of temperament (novelty seeking, harm avoidance, reward dependence, persistence) and three dimensions of character (self-directedness, cooperativeness, self-transcendence). Temperament dimensions are supposed to be inherited and related with specific neurotransmitters, while character dimensions are supposed to develop during life (Cloninger, 1994). ET showed higher scores in novelty seeking (Adan et al., 2010a; Caci et al., 2004; Randler \& Saliger, 2011) and lower in harm avoidance (Adan et al., 2010a). There was no relationship in reward dependence. Concerning persistence, higher scores have been found in MT (Adan et al., 2010a; Caci et al., 2004, Randler \& Saliger, 2011). Concerning character, ET had lower scores in selfdirectedness (Adan et al., 2010a) and cooperation (Randler \& Saliger, 2011), while ET were higher in self-transcendence (Randler \& Saliger, 2011).

\section{Alternative Five Factor Model (AFFM)}

The AFFM (Zuckerman, 2002) was used by Muro et al. $(2009,2011)$ and these authors showed that MT subjects had significantly higher scores than ET and NT subjects in activity, and in its subscales general activity and work activity. Muro et al. (2009) found an interaction: MT men showed higher scores than ET and NT in neuroticism-anxiety and women had the opposite pattern. In women, Muro et al. (2011) reported that MT women had higher scores than ET and NT women on activity, and its subscales general activity and work activity, while ET women scored higher than MT women on aggression-hostility, impulsive sensation seeking, and its subscale sensation seeking. The higher level in activity in MT might be related to higher cortisol levels, at least at awakening (Kudielka et al., 2006, 2007; Randler \& Schaal, 2010).

\section{Other personality measurements}

Díaz-Morales (2007) used the Millon Index of Personality Styles (MIPS). ET preferred imaginative, feeling-guided, innovation-seeking thinking styles, while MT preferred realistic, thought-guided and conservation-seeking thinking styles. ET preferred unconventional behaving styles while MT preferred dutiful behaving styles. By using Zuckerman's Sensation-Seeking Scale, Tonetti et al. (2010) reported higher scores in ET compared to MT in SSS-V total score and all subscales, except boredom susceptibility. When comparing different facets of impulsivity, 
Adan et al. (2010b) reported that MT obtained lower scores in dysfunctional impulsivity than the NT and ET. By using the Portrait Values Questionnaire (PVQ; Schwartz, 2003), Vollmer and Randler (2012) found that morningness was correlated with higher acceptance of social values (conservation and self-transcendence), while eveningness was correlated with higher preference for individual values (openness to change and self-enhancement). Based on the Maudesley Personality Inventory, Hsu et al. (2012) reported that ET of both sexes scored higher than the MT in novelty seeking, harm avoidance, and neurotic personality characteristics, but lower than MT in extraversion and social desirability. Concerning reward dependence, ET scored lowest for males, but there was no difference for females.

Morningness also was positively related to proactivity (Randler, 2009b) and subjective well-being or life quality (Biss, 2012; Jankowski, 2012; Lázár, 2012; Randler, 2008). ET showed a less adaptive emotional profile than MT and NT, who showed a relatively similar emotional pattern. Focus and order (facets of Control), energy (facet of Volition), caution (facet of Inhibition), and problem facing (facet of Coping) were particularly low in ET and high in MT (Ottoni et al. 2012). Finally, Díaz-Morales et al. (2008) found that morningness is negatively related to indecision and procrastination, two behaviours that are typical in individuals who score low in conscientiousness.

\section{Personality traits relationships}

As a summary, research on personality and CT indicates that ET subjects are more extraverted, impulsive, novelty-seeking, open-minded and tend more to psychoticism (psychopathology), while MT ones tend to be more introverted, conscientious, agreeable, persistent and emotionally stable.

One interesting fact is that eveningness was relatively strong related to extraversion when using the EPI, while nearly no study focusing on the BFI found a significant relationship between these two variables. However, extraversion is one dimension that is quite similar across EPI, BFI and AFFM (Aziz \& Jackson 2001; Zuckerman et al., 1993).

Nevertheless, some authors suggest the relationship between CT and personality might have to do with the different theoretical models used to assess personality (Randler, 2008c; Tsaousis, 2010), rather than with the different measures used to assess morningness, as none of them seems to be psychometrically superior (Di Milia et al., 2008). Indeed, it might depend on the personality inventories used: the BFI is a psycholexical approach (based on adjectives from a lexicon), while EPQ, TCI, and AFFM are based on biological theories/models. Furthermore, it may also be dependent on the aspect or subcomponent of extraversion measured - e.g. activity or impulsivity. Tankova et al. (1994) suggested that it is probably due to the impulsive component 
inherent to the extraversion dimension (Adan et al., 2010b; Caci et al., 2005b), and especially dysfunctional impulsivity (Adan et al. 2010b), which could be responsible for the relationship between extraversion and eveningness. Indeed, Eysenck's extraversion is positively correlated with novelty seeking of the TCI and negatively with harm avoidance (Zuckerman \& Cloninger, 1996). However, Muro et al. further (2009) suggested that previous correlations between morningness and Eysenck's extraversion were probably due to the activity component inherent to extraversion, rather than impulsivity or sociability components (Caci et al., 2005b; Larsen, 1985; Tankova et al., 1994). The ZKPQ-activity component, in turn, is correlated with the persistence component of the TCI, which supports Muro et al.'s (2009) suggestion (Zuckerman \& Cloninger, 1996).

Similarly, in most studies ET scored higher in the impulsive sensation-seeking dimension of the ZKPQ, which is considered equivalent to the Big Five's conscientiousness factor reversed and very close to Cloninger's novelty seeking (Zuckerman \& Cloninger, 1996; Adan et al. 2010a; Tonetti et al., 2010). Thus, it seems a basic relationship between eveningness and novelty/sensation seeking.

\section{PSYCHIATRIC DISORDERS: CLINICAL IMPLICATIONS}

The morningness and eveningness dimension shares some behavioral components with mental disorders. Among the symptoms that are often associated with the presence of psychiatric symptoms and CT are alterations in appetite, in the sleep/wake cycle, in cognition, and in activity, which together can lead to social damage. The majority of these studies have shown that ET is associated with a number of psychiatric symptoms.

CT have also been studied at the genetic level to determine whether clock genes are involved in the link between $\mathrm{CT}$ and mental disorders, but controversial results have been observed (Lee et al., 2010; Osland et al., 2011; Serretti et al., 2010). The results from genetic studies suggest the polymorphism may not be the only factor responsible for the association between mental disorders and CT. Instead, it is likely that this relationship is generated by behavioral habits that expose individuals to different zeitgebers, which, in turn, modify the internal clock and potentially predispose individuals to mental disorders. As a test of this hypothesis, one study reported that ET presented higher levels of chronic work-related fatigue, exhibited less regular social rhythms, and were exposed to lower levels of light during their waking hours compared to NT and MT (Martin et al., 2012). Additionally, the relationship between depressive mood and eveningness in rural populations was mediated by differences between week and weekend sleep schedules (social jetlag) (Levandovski, 2011). Social rhythms are known to interfere with the synchronization of biological rhythms and consequently cognitive 
and behavior alteration. Thus, the study of social rhythms may lead to a reflection on the temporal organization of society and may support the development of a new approach to treat mental disorders.

\section{Mood Disorders}

Mood disorders, especially those related to depression, are among the most prevalent mental impairments, approximately $10 \%$ to $15 \%$ (Lepine \& Briley, 2011). The World Health Organization estimates that unipolar major depression will be the leading disease burden by the year 2030. Both clinical and sub-clinical depressions are related to a higher prevalence of disabilities. There are different subtypes of depression, but certain parameters are present in almost all of them, such as disturbed sleep and changes in the circadian rhythms of cortisol, $\mathrm{ACTH}$, melatonin and other endocrine and metabolic parameters (Soria \& Urretavizcaya, 2009). Figure 1 represents the main theory related to the etiology of mood disorders that involves amino neurotransmitters, such as noradrenaline, serotonin and dopamine. These neurotransmitters are intrinsically connected to melatonin production.

\section{Insert Figure 1}

A clear example of the link between chronobiology and depressive manifestation can be observed in Seasonal Affective Disorder (SAD). The circadian rhythm disorder may be caused by desynchronization between the light/dark cycle and the human biological clock during seasons with shorter photoperiods (Benedetti et al., 2007; Lewy et al., 2006; Rosenthal et al., 1984). Similarly, in bipolar disease, the oscillations between mania and depression may occur in regular cycles. Furthermore, inter-individual differences in sleep timing, duration, and morning or evening preferences are associated with changes in circadian processes, sleep homeostatic processes, or both (Schmidt et al., 2012).

Several follow-up studies showed that circadian timing is drastically delayed in patients with bipolar disorder (Giglio et al., 2010; Soreca et al., 2009), SAD (Elmore et al., 1993) and major depressive disorder (Drennan et al., 1991; Soria \& Urretavizcaya, 2009). Circadian misalignment and sleep disruptions in patients with mood disorders have been linked to abnormal daily patterns of gene expression, hormonal secretion, body temperature, and cognitive and behavioral functions (Wulff et al., 2010). An additional indication that circadian misalignment contributes to depressive symptoms is the finding that ET people are prone to depressive symptoms (Chelminski et al., 1999; Giannotti et al., 2002; Hidalgo et al., 2009, Kitamura et al., 2010).

The internal desynchronization may be a major factor with regard to mood. Studies in healthy individuals using different measurement instruments have shown that the depressive 
symptoms that present higher discriminate coefficients among CT are those related to sadness, inner tension, sleep reduction and pessimism (Hidalgo et al., 2009). Thus, depressive symptoms present a potential confounding effect in CT studies. In a sample of depressive patients, the sleep variables of CT and sleep quality did not significantly predict suicidal ideation if the effect of depressive symptoms was controlled (Selvi, 2010).

ET has also been associated with higher levels of depression that may be moderated by age (Kim et al., 2010) and mediated by sexual hormones (for further information see biological differences section). High testosterone levels lead to eveningness (Randler et al., 2012), and menstrual symptoms are more significant in ET girls (Negriff \& Dorn, 2009). This evidence indicates that a phase delay may be a part or consequence of the diagnosis of mental disorders (such as depression, anxiety and eating disorders) or may be an associated risk factor linked by sexual development (Schneider et al., 2011; Schubert \& Randler, 2008). Therefore, the next step to clarify the causality relation is to develop transcultural studies with a homogenous methodology in longitudinal studies.

The evidence that chronodisruption can be linked to depression, has opened a new approach for its treatment. Photic treatment is based on the assumption that exposure to light inhibits the production of melatonin, thereby reducing the symptoms of depression (Lewy et al., 1987; Wirz-Justice et al., 2005). Studies have also found that physical exercise influences rhythms and improves mood after weeks of early morning training (Peiser, 2009). But, it will also be necessary to develop randomized clinical trials to test the efficacy and the effectiveness of chronobiological interventions, such as melatonin, light exposure, and social rhythm regulation, as well as to test the best time of day for eating, sleeping and exercising.

\section{Eating Disorders}

Leptin and ghrelin are hormones that act directly on the timing of food ingestion and regulate appetite. Leptin is a hormone produced in adipose tissue (Figure 1) that acts directly under a timing system regulating food ingestion. It has been hypothesized that leptin is involved in the etiology of depressive symptoms, which are very common among obese patients. Obviously, there is a neuronal correlation among mental disorders, despite the academic effort to classify each syndrome into mental categories. For example, mood and eating disorders appear to be connected via hormones that regulate not only feeding but also neuronal activity in the mesolimbic dopaminergic pathway. In particular, leptin reduces the firing rates of dopaminergic neurons, which indicates that leptin exerts a direct influence on dopamine neurons via leptin receptors (Dibner et al., 2010) (Figure 1). 
Therefore, chronodisruption in appetite hormones may provoke a disregulation in the aminergic pathway and vice versa. A study that investigated the relationship between leptin levels and ghrelin as well as symptoms of depression, anxiety and stress in women demonstrated a significantly negative relationship between leptin and the severity of depressive symptoms and anxiety (Lawson et al., 2011). Females present a greater expression of clock genes in adipose tissue, and consequently it has been hypothesized that this sexual dimorphism may account for the different CT of males and female (Gomez-Abellán et al., 2012).

Some syndromes are important human physiological situations in which we can observe evidence of chronobiology manifestations through altered behavior. Normally, energy intake varies in intensity throughout the day. In the natural environment, there is an increase in food intake and energy consumption at night compared with morning (de Castro, 2004). One example of abnormal eating behavior due to temporal alteration is the Night Eating Syndrome (NES). The etiology of NES might be explained by the desynchronization of temporal order and internal difficulties in synchronizing with environmental cycles, such as delayed eating times. Reinforcing this hypothesis, one study has shown a positive correlation between eveningness and NES (O'Reardon, 2004).

\section{Addictions}

Recent chronobiological studies show that drug consumption, even at moderate doses, has a negative effect on circadian rhythmic expression. The amplitude of some circadian rhythms is lower or even disappears in extreme cases, which suggests a lesser quality of the wake and sleep periods. A recent study by Reinberg et al. (2010) found a glass of red wine during dinner (20.5 g alcohol / $24 \mathrm{~h}$ ) is sufficient to desynchronize circadian time organization. The effects of drug addiction on the circadian rhythmic expression can persist for weeks or even months after drug use has ceased (Adan, 2012).

The lack of regularity in circadian rhythms has been mostly studied with alcohol (Conroy et al., 2012; Danel \& Touitou, 2004; Huang et al., 2010; Rupp et al., 2007), tobacco (Adan \& Sanchez-Turet, 1995, 2000; Adan et al., 2004), and cocaine dependence (McClung et al., 2005; Uz et al., 2005). However, it seems that the data compiled to date may be generalized to most types of drugs, independently of their pharmacological effects on the organism (Perreau-Lenz \& Spanagel, 2008; Adan, 2012).

Adan's (1994) pioneering study found significant differences in the consumption of legal psychoactive substances (nicotine, alcohol and caffeine). ET subjects reported higher consumption -sporadic and habitual- of the three substances. Subsequent international studies have confirmed this observation, and this is of special relevance for adolescent and adult 
populations (Andershed, 2005; Gau et al., 2007; Urbán et al., 2011; Giannotti et al., 2002; Wittmann et al., 2006). Prat \& Adan (2011) have also found ET subjects consumed more illegal drugs (cannabis, ecstasy and cocaine) and hazardous alcohol use than MT. This has become a social and health problem with potentially serious consequences in a short-term (accidents, unwanted pregnancies, assault) beyond the risk of developing an addictive disorder. These results alert us to the need for further research on $\mathrm{CT}$ and heavy episodic drinking, although in many cases drug poly-consumption is present.

Although there are many other elements that also participate in the onset and maintenance of drug consumption, CT is certainly one of them. It has been hypothesized that ET subjects begin drug consumption with stimulants in order to adjust their degree of daytime activation to the socio-environmental demands when their alertness is low, whereas the use of depressors tends to appear towards the end of the day, when their degree of activation exceeds that required for the demands. In the initial phases of consumption, individuals who are prone to chronobiological vulnerability (ET) may obtain superior effects of regulation in their activation and reinforcement, and this will favor behavior maintenance (Adan \& Sánchez-Turet, 2000; Adan et al., 2008; Prat \& Adan, 2011). However, the spiral of stress will appear with chronic consumption, and it may be more intense and of more dramatic consequences in the ET individuals (Adan, 2012). There is also evidence that circadian genes play a role in addiction. The circadian gene Clock is a direct regulator of the dopaminergic activity in the brain areas of reward (Huang et al., 2010; Rosenwasser, 2010), Perl has been related to rewarding properties (McClung, 2007), and Per2 has been proven essential to inhibit the sensitization and reward to the effects of drugs (PerreauLenz \& Spanagel, 2008; Perreau-Lenz et al., 2009).

It is important to remember that mood disorder, obesity, metabolic syndrome and adicction are risk factors for diabetes, hypertension, and vascular disease, among others. Thus, an effective health policy should be based on primary prevention, which must consider education and intervention to diminish chronodisruption and prevent the risk of prevalent disabilities. The link between psychiatric disorders and CT is in its infancy and functional neuroimaging studies carried out in the future will advance our understanding and go towards the integration of molecular and biochemical aspects. Studies have already investigated the neurostructural basis for the relationship between sleep and mental disorders, and the prefrontal cortex and striatum have been implicated in differences among CT. As these areas are related to mood variations, these structures likely constitute one of the underlying mechanisms in the relationship between depressive mood and ET (Hasler et al., 2012). The other structure that has been implicated in the correlation between sleep-wake regulation and CT is the posterior hypothalamic region, which is also an important memory region (Schmidt et al., 2012). These findings may explain the 
difference between ET and MT in perceived performance on memory tests, despite the lack of differences in actual performance on the Word-Pairs Associated and Word List with Emotional Content or Stroop tests (Hidalgo et al., 2004; Schmidt et al., 2012).

\section{CONCLUDING REMARKS}

The differences among CT should be understood from a wide perspective, leading us to state that they are associated with different lifestyles. Although we should avoid a simplistic shortcut of associating ET to some negative aspects, the data point to the idea that an ET pattern is a risk factor for some disorders, whereas MT is a protection factor. The habits of the MT are healthier in general than those found in the ET. Although this is important all along the life cycle, it seems more crucial in adolescence, when the adult lifestyle is beginning to take shape, and in the ageing period, when health problems related to life habits are more frequent. Hence, it may be of interest to consider this variable in a bio-psycho-social health model, in order to design more efficient preventive and therapeutic approaches.

This is a new field of interest to professionals in many different areas (research, labor, academic, and clinic) which must be formed and well informed on this knowledge in order to integrate chronobiological aspects in their daily practice as needed. Therapeutic approaches to psychiatric disorders should take into account circadian rhythmicity. In many cases it may suffice to establish regular time patterns of sleep-wake, meals and daily activity with a tendency towards a MT pattern of functioning. Other strategies, such as exposition to light therapy and melatonin administration, according to each case, may also be effective in clinical management and as protective measures against relapse of mental health disorders. Understanding the genetics underlying CT could help to identify individuals who are at risk or vulnerable to certain life styles or health disorders. Prevention should also include these findings in their initiatives. Involving chronobiology in prevention implies not only promoting healthy leisure activities or "what to do", but rather placing such activities in appropriate daytime temporal moments or "when to do" them.

Acknowledgements. AA supported by a grant from the Spanish Ministry of Science and Innovation (PSI2009-12300), SNA was supported by grants from the BBSRC (BB/F022883/1) and AFOSR (FA-9550-08-1-0080), MPH Supported by a grant from CAPES, CNPq, FAPERGS and FIPE/ HCPA-Brasil, CR was supported by a sabbatical leave. To Prof. Yvan Touitou for considering the importance of the issue and for providing an opportunity for this review to be published in Chronobiology International. 
Declaration of interest. The authors report no conflicts of interest. The authors alone are responsible for the contents and writing of the paper.

\section{REFERENCES}

Achari KV, Pati AK. (2007). Morningness-eveningness preference in Indian school students as function of gender, age, and habitat. Biol. Rhythm Res. 38:1-8.

Adan A. (1991). Influence of morningness-eveningness preference in the relationship between body temperature and performance: A diurnal study. Pers. Ind. Diff. 12:1159-1169.

Adan A. (1993). Circadian variations in psychological measures: A new classification. Chronobiologia 20:145-162.

Adan A. (1994). Chronotype and personality factors in the daily consumption of alcohol and psychostimulants. Addiction, 89, 455-462.

Adan A. (2012). A chronobiological approach to addiction. J. Subs. Use (in press)

Adan A, Almirall H. (1991). Horne and Östberg morningness-eveningness questionnaire: A reduced scale. Pers. Ind. Diff. 12:241-253.

Adan A, Lachica J, Caci H, Natale V. (2010a). Circadian typology and temperament and character personality dimensions. Chronobiol. Int. 27:181-193.

Adan A, Natale V. (2002). Gender differences in morningness-eveningness preference. Chronobiol. Int. 19:709-720.

Adan A, Natale V, Caci H. (2008). Cognitive strategies and circadian typology. In: Léglise AL (Ed.). Progress in circadian rhythms research. Nova Biomedical Books. New York: Nova Science Publishers, Inc, pp. 141-161.

Adan A, Natale V, Caci H, Prat G. (2010b). Relationship between circadian typology and functional and dysfunctional impulsivity. Chronobiol. Int. 27:606-619.

Adan A, Prat G, Sánchez-Turet M. (2004). Effects of nicotine dependence on diurnal variations of subjective activation and mood. Addiction 98:1599-1607.

Adan A, Sánchez-Turet M. (1995). Smoking effects on diurnal variations of cardiovascular parameters. Int. J. Psychophysiol. 20:189-198.

Adan A, Sánchez-Turet M. (2000). Effects of smoking on diurnal variations of subjective activation and mood. Hum. Psychopharmacol. Clin. Exp. 15:287-293.

Adan A, Sanchez-Turet M. (2001). Gender differences in diurnal variations of subjective activation and mood. Chronobiol. Int. 18:491-502.

Akerstedt T (2003). Shift work and disturbed sleep/wakefulness. Occup. Med. (Lond) 53:89-94.

Andershed K-A. (2005). In sync with adolescence: the role of morningness-eveningness in adolescence. New York: Springer. 
Anderson MJ, Petros TV, Beckwith BE, Mitchell WW, Fritz S. (1991). Individual differences in the effect of time of day on ling term memory access. Am. J. Psychol. 104:241-255.

Andretic R, Franken P, Tafti M. (2008). Genetics of sleep. Annu. Rev. Genet. 42: 361-388.

Archer SN, Robilliard D, Skene DJ, Smits MG, Williams A, Arendt J, von Schantz M. (2003). A length polymorphism in the circadian clock gene Per3 is linked to delayed sleep phase syndrome and extreme diurnal preference. Sleep 26:413-415.

Archer SN, Viola AU, Kyriakopoulou V, von Schantz M, Dijk DJ. (2008). Inter-individual differences in habitual sleep timing and entrained phase of endogenous circadian rhythms of BMAL1, PER2 and PER3 mRNA in human leukocytes. Sleep 31:608-617.

Archer SN, Carpen JD, Gibson M, Lim GH, Johnston JD, Skene DJ, von Schantz M. (2010). Polymorphism in the PER3 promoter associates with diurnal preference and delayed sleep phase disorder. Sleep 33:695-701.

Arendt J. (2006). Melatonin and human rhythms. Chronobiol. Int. 23:21-37.

Arendt J. (2009). Managing jet lag: Some of the problems and possible new solutions. Sleep Med. Rev. 13:249-256.

Aziz S, Jackson CJ. (2001). A comparison between three and five factor models of Pakistani personality data. Pers. Ind. Diff. 31:1311-1319.

Baehr E, Revelle W, Eastman CI. (2000). Individual differences in the phase and amplitude of the human circadian temperature rhythm: With an emphasis on morningness-eveningness. $J$. Sleep Res. 9;117-127.

Bailey SL, Heitkemper MM. (1991). Morningness-eveningness and early morning salivary cortisol levels. Biol. Psychol. 32:181-192.

Bailey SL, Heitkemper MM. (2001). Circadian rhythmicity of cortisol and body temperature: Morningness-eveningness effects. Chronobiol. Int. 18:249-261.

Barclay NL, Eley TC, Buysse DJ, Archer SN, Gregory AM. (2010). Diurnal preference and sleep quality: same genes? A study of young adult twins. Chronobiol. Int. 27:278-296.

Barclay NL, Eley TC, Mill J, Wong CC, Zavos HM, Archer SN, Gregory AM. (2011). Sleep quality and diurnal preference in a sample of young adults: associations with 5HTTLPR, PER3, and CLOCK 3111. Am. J. Med. Genet. B Neuropsychiatr. Genet. 156B:681-690.

Benedetti F, Barbini B, Colombo C, Smeraldi E. (2007). Chronotherapeutics in a psychiatric ward. Sleep Med Rev. 11:509-522.

Benloucif S, Guico MJ, Reid KJ, Wolfe LF, L'Hermitage-Baleriaux M, Zee PC. (2005). Stability of melatonin and temperature as circadian phase markers and their relation to sleep in humans. J. Biol. Rhythms 20:178-188. 
Besoluk S, Önder I, Deveci I. (2011). Morningness-eveningness preferences and academic achievement of university students. Chronobiol. Int. 28:118-125.

Biss RK, Hasher L. (2012). Happy as a lark: Morning-type younger and older adults are higher in positive affect. Emotion doi: 10.1037/a0027071. (in press)

Blatter K, Cajochen C. (2007). Circadian rhythms in cognitive performance: methodological constrains, protocols, theoretical underpinnings. Physiol. Behav. 90:196-208.

Bohle P, Tilley AJ, Brown S. (2001). A psychometric evaluation of the Early/Late Preferences Scale. Ergonomics 44:887-900.

Borisenkov MF, Perminova EV, Kosova AL. (2010). Chronotype, sleep length, and school achievement of 11- to 23-year-old students in northern European Russia. Chronobiol. Int. 27:1259-1270.

Borisenkov MF, Perminova EV, Kosova AL. (2012). Impact of perinatal photoperiod on the chronotype of 11- to 18-years-olds in northen European Russia. Chronobiol. Int. 29:305310.

Caci H, Adan A, Bohle P, Natale V, Pornpitakpan C, Tilley A. (2005a). Transcultural properties of the composite scale of morningness: The relevance of the "morning affect" factor. Chronobiol. Int. 22:523-540.

Caci H, Deschaux O, Adan A, Natale V. (2009). Comparing three morningness scales: Age and gender effects, structure and cut-off criteria. Sleep Med. 10:240-245.

Caci H, Mattei V, Bayle FJ, Nadalet L, Dossios C, Robert P, Boyer P. (2005b). Impulsivity but not venturesomeness is related to morningness. Psychiatr. Res. 134:259-265.

Caci H, Nadalet L, Staccini P, Myquel M, Boyer P. (1999). Psychometric properties of the French version of the Composite Scale of Morningness in adults. Eur. Psychiatr. 14:284-290.

Caci H, Robert P, Boyer, P. (2004). Novelty seekers and impulsive subjects are low in morningness. Eur. Psychiatr. 19:79-84.

Carpen JD, Archer SN, Skene DJ, Smits M, von Schantz M. (2005). A single-nucleotide polymorphism in the 5 '-untranslated region of the hPER2 gene is associated with diurnal preference. J. Sleep Res. 14:293-297.

Carpen JD, von Schantz M, Smits M, Skene DJ, Archer SN (2006). A silent polymorphism in the PER1 gene associates with extreme diurnal preference in humans. J. Hum. Genet. 51:1122-1125.

Cattell RB, Eber HW, Tatsuoka MM. (1970). Handbook for the Sixteen Personality Factor Questionnaire. IPAT, Champaign, IL.

Cavallera GM, Boari G, Giudici S, Ortolano A. (2011). Cognitive parameters and morning and evening types: two decades of research (1990-2099). Percept. Mot. Skills 112: 649-665. 
Cavallera GM, \& Giudici S. (2008). Morningness and eveningness personality: A survey in literature from 1995 up till 2006. Pers. Ind. Diff. 44:3-21.

Chang AM, Buch AM, Bradstreet DS, Klements DJ, Duffy JF. (2011). Human diurnal preference and circadian rhythmicity are not associated with the CLOCK $3111 \mathrm{C} / \mathrm{T}$ gene polymorphism. J. Biol. Rhythms 26:276-279.

Chelminski I, Ferraro FR, Petros T, Plaud JJ. (1997). Horne and Östberg questionnaire: A score distribution in a large sample of young adults. Pers. Ind. Diff. 23:647-652.

Chelminski I, Ferraro FR, Petros T, Plaud JJ. (1999). An analysis of the "eveningnessmorningness" dimension in "depressive" college students. J. Affect. Disord. 52:19-29.

Chelminski I, Petros T, Plaud JJ, Ferraro FR. (2000). Psychometric properties of the reduced Horne and Östberg. Pers. Ind. Diff. 29:469-478.

Ciarkowska W. (1997). Time of day effect on logical reasoning and heart rate change. Stud. Psychol. 35:141-163.

Clarisse R, Le Floc'h N, Kindelberger C, Feunteun P. (2010). Daily rhythmicity of attention in morning-vs. evening-type adolescents at boarding school under different psychosociological testing conditions. Chronobiol. Int. 27:826-841.

Cloninger CR. (1994). Temperament and personality. Currt Biol. 4:266-273.

Colquhoun WP. (1971). Biological rhythms and human performance. London: Academic Press.

Conroy DA, Hairston IS, Arnedt JT, Hoffmann RF, Armitage R, Brower KJ. (2012). Dim light melatonin onset in alcohol-dependent men and women compared with healthy controls. Cronobiol. Int. 29:35-42.

Corbera X, Grau C. (1993). Diurnal type and hemispheric asymmetry. Cortex 29:519-528.

Corbera X, Grau C, Vendrell P. (1993). Diurnal oscillations in hemispheric performance. J. Clin. Exp. Neuropsychol. 15:300-310.

Costa PT, McCrae RR. (1992). Revised NEO Personality Inventory (NEO PI-R) and NEO FiveFactor Inventory (NEO-FFI): Professional manual. Odessa, FL: Psychological Assessment Resources.

Drennan MD, Klauber MR, Kripke DF, Goyette LM. (1991). The effects of depression and age on the Horne-Ostberg morningness-eveningness score. J. Affect. Disord. 23:93-98.

Danel T, Touitou Y. (2004). Chronobiology of alcohol: from chronokinetics to alcohol-related alterations of the circadian system. Chronobiol. Int. 21:923-935.

de Castro JM. (2004). The time of day of food intake influences overall intake in humans. J. Nutr. 134:104-111. 
deYoung CG, Hasher L, Djikic M, Criger B, Peterson JB. (2007). Morning people are stable people: Circadian rhythm and the higher-order factors of the Big Five. Pers. Ind. Diff. 43:267-276.

Díaz-Morales JF. (2007). Morning and evening-types: exploring their personality styles. Pers. Ind. Diff. 43:769-778.

Di Milia L, Smith PA, Folkard S. (2004). Refining the psychometric properties of the circadian type inventory. Pers. Ind. Diff. 36:1953-1964.

Di Milia L. (2005). A psychometric evaluation and validation of the Preferences Scale Chronobiol. Int. 22:679-693.

Di Milia L, Smith PA, Folkard S. (2005). A validation of the revised circadian type inventory in a working sample. Pers. Ind. Diff. 39:1293-1305.

Di Milia L, Bohle, P. (2009). Morningness or morning affect? A short composite scale of morningness. Chronobiol. Int. 26:494-509.

Di Milia L, Wikman R, Smith P. (2008). Additional psychometric evidence and construct validity for a revised Preferences Scale of Morningness. Chronobiol. Int. 25:776-787.

Di Milia L, Muller H. (2012). Does impression management impact the relationship between morningness-eveningness and self-rated sleepiness? Pers. Ind. Diff. 36:1953-1964.

Dibner C, Schibler U, Albrecht U. (2010). The mammalian circadian timing system: organization and coordination of central and peripheral clocks. Annu. Rev. Physiol. 17:517-549.

Dijk DJ, Archer SN (2009). PERIOD3, circadian phenotypes, and sleep homeostasis. Sleep Med. Rev. 14:151-160.

Dockray S, Steptoe A. (2011). Chronotype and diurnal cortisol profile in working women: Differences between work and leisure days. Psychoneuroendocrinol. 36:649-655.

Duffy JF, Cain SW, Chang AM, Phillips KJ, Münch MY, Gronfier C, Wyatt JK, Dijk DK, Wright KP, Czeisler CA. (2011). Sex differences in the near-24-hours intrinsic period of the human circadian timing system. Proc. Natl. Acad. Sci. USA 108;15602-15608.

Duffy JF, Dijk DJ, Hall EF, Czeisler CA. (1999). Relationship of endogenous circadian melatonin and temperature rhythms to self-reported preference for morning or evening activity in young and older people. J. Investi. Med. 47:141-150.

Duffy JF, Rimmer DW, Czeisler CA. (2001). Association of intrinsic circadian period with morningness-eveningness, usual wake time, and circadian phase. Behav. Neurosci. 115:895-899.

Eastman CI, Burgess H. (2009). How to travel the world without jet lag. Sleep Med. Rev. 4:241255. 
Ebisawa T, Uchiyama M, Kajimura N, Mishima K, Kamei Y, Katoh M, Watanabe T, Sekimoto M, Shibui K, Kim K, Kudo Y, Ozeki Y, Sugishita M, Toyoshima R, Inoue Y, Yamada N, Nagase T, Ozaki N, Ohara O, Ishida N, Okawa M, Takahashi K, Yamauchi T. (2001). Association of structural polymorphisms in the human period 3 gene with delayed sleep phase syndrome. EMBO Rep. 2:342-346.

Elmore SK, Dahl K, Avery DH, Savage MV, Brengelmann GL. (1993). Body temperature and diurnal type in women with seasonal affective disorder. Health Care Women Int. 14:1726.

Eysenck HJ, Eysenck SBG. (1975). Manual of the Eysenck Personality Questionnaire. London: Hodder \& Stoughton.

Eysenck SBG, Eysenck HJ, Barrett P. (1985). A revised version of the psychoticism scale. Pers. Ind. Diff. 6:21-29.

Fabbri M, Antonietti A, Gioirgetti M, Tonetti L, Natale V. (2007). Circadian typology and style of thinking differences. Learn. Indiv. Diff. 17:175-180.

Fabbri M, Mencarelli C, Adan A, Natale V. (2012) Time of day and circadian typology on memory retrieval. Biol. Rhythm Res. (in press)

Fan J, MccCandliss BD, Sommer T, Raz A, Posner MI. (2002). Testing the efficiency and independence of attentional networks. J Cogn. Neurosci. 14:340-347.

Fan J, Posner M. (2004). Human attentional networks. Psychiatr. Prax. 31:S210-S214.

Flower DJC, Irvine D, Folkard S. (2003). Perception and predictability of travel fatigue after longhaul flights: A retrospective study. Aviat. Space Enviro. Med. 74:173-179.

Folkard S. (1990). Circadian performance rhythms: some practical and theoretical implications. Philosoph. Trans. Roy. Soc. Lond. B327:543-553.

Folkard S, Monk TH, Lobban MC. (1979). Towards a predictive test of adjustment to shift work. Ergonomics 22:79-91.

Franken P, Dijk DJ (2009). Circadian clock genes and sleep homeostasis. Eur. J. Neurosci. 29:1820-1829.

Furnham A, Hughes K. (1999). Individual difference correlates of nightwork and shift-work rotation. Pers. Ind. Diff. 26:830-848.

Gaina A, Sekine M, Kakayama H, Takashi Y, Hu L, Sengoku K, Kagamimori S. (2011). Morning-evening preference: Sleep pattern espectrum and lifestyle habits among Japanese junior high school pupils. Chronobiol. Int. 23:607-621.

Gale C, Martyn C. (1998). Larks and owls and health, wealth and wisdom. Brit. Med. J. 317:1675-1677. 
Gamble KL, Motsinger-Reif AA, Hida A, Borsetti HM, Servick SV, Ciarleglio CM, Robbins S, Hicks J, Carver K, Hamilton N, Wells N, Summar NK, McMahon DG, Johnson CH. (2011). Shift work in nurses: Contribution of phenotypes and genotypes to adaptation. PlosOne 6:e18395.

Gau SS, Shang CY, Merikangas KR, Chiu YN, Soong WT, Cheng AT (2007). Association between morningness-eveningness and behavioral / emotional problems among adolescents. J. Biol. Rhythms 22:268-274.

Gau SS, Soong WT. (2003). The transition of sleep-wake patterns in early adolescence. Sleep 26:449-454.

Giampietro M, Cavallera G. (2007). Morning and evening types and creative thinking. Pers. Ind. Diff. 42:453-463.

Giannotti F, Cortesi F, Sebastiani T, Ottaviano S. (2002). Circadian preference, sleep and daytime behaviour in adolescence. J. Sleep Res. 11:191-199.

Gibertini M, Graham C, Cook MR. (1999). Self-report of circadian type reflects the phase of the melatonin rhythm". Biol. Psychol. 50:19-33.

Giglio LM, Magalhães PV, Andersen ML, Walz JC, Jakobson L, Kapczinski F. (2010). Circadian preference in bipolar disorder. Sleep Breath. 14:153-155.

Gillooly PB, Smolensky MH, Albright DL, Hsi B, Thorne DR. (1990). Circadian variation in human performance evaluated by Walter Reed Perfomance Assessment Battery. Chronobiol. Int. 7:143-153.

Godfrey R, Ramsay R. (2002). Identifying some determinants of “jet lag” and its symptoms: A study of athletes and other travellers. Br. J. Sports Med. 36:54-60.

Gómez-Abellán P, Madrid JA, Ordovás JC, Garauleta M. (2012). Chronobiological aspects of obesity and metabolic syndrome. Endocrinol. Nutr. 59:50-61.

Gray EK, Watson D. (2002). General and specific traits of personality and their relationship to sleep and academic performance. J. Pers. 70:177-206.

Griefahn B, Künemund C, Golka K, Their R, Degen G. (2002). Melatonin synthesis: A possible indicator of intolerance to shift work. Am. J. Ind. Med. 42:427-436.

Griefahn B, Robens S. (2008). The cortisol awakening response: A pilot study on the effects of shift work, morningness and sleep duration. Psychoneuroendocrinol. 33:981-988.

Groeger JA, Viola AU, Lo JC, von Schantz M, Archer SN, Dijk DJ. (2008). Early morning executive functioning during sleep deprivation is compromised by a PERIOD3 polymorphism. Sleep 31:1159-1167. 
Groeger JA, Zijlstra FR, Dijk DJ. (2004). Sleep quantity, sleep difficulties and their perceived consequences in a representative sample of some 2000 British adults. J. Sleep Res. 13:359-371.

Guerrien A, Leconte-Lambert C, Leconte L. (1993). Time of day effects on attention and memory efficiency: is the chronopsychology a method for studying the functioning of the human subjects? Psychol. Belg. 33:159-170.

Gupta S, Pati AK. (1994). Characteristics of circadian rhythm in six variables of morning active and evening active healthy human subjects. Ind. J. Physiol. Pharmacol. 38:101-107.

Guthrie JP, Ash RA, Bendapudi V. (1995). Additional validity evidence for a measure of morningness. J. App. Psych. 80:186-190.

Hagenauer MH, Perryman JI, Lee TM, Carskadon MA. (2009). Adolescent changes in the homeostatic and circadian regulation of sleep. Develop. Neurosc. 31:276-284.

Harada T, Kobayashi R, Wada K, Nishihara R, Kondo A, Akimitsi O, Noji T, Taniwaki N, Nakade M, Krejci M, Takeuchi H. (2011). Effects of birth season on circadian typology appearing in japanese young children aged 2 to 12 years disappears in older students aged 18 to 25 years. Chronobiol. Int. 28:638-642.

Hasan S, Santhi N, Lazar AS, Slak A, Lo J, von Schantz M, Archer SN, Johnston JD, Dijk DJ. (2012). Assessment of circadian rhythms in humans: comparison of real-time fibroblast reporter imaging with plasma melatonin. Faseb J. 26:2414-2423.

Hasher L, Chung C, May CP, Foong N. (2002). Age, time of testing, and proactive interference. Can. J. Exp. Psychol. 56:200-207.

Hasler BP, Germain A, Nofzinger EA, Kupfer DJ, Krafty RT, Rothenberger SD, James JA, Bi W, Buysse DJ. (2012). Chronotype and diurnal patterns of positive affect and affective neural circuitry in primary insomnia. J Sleep Res. (in press)

Hidalgo MP, Zanette CB, Pedrotti M, Souza CM, Nunes PV, Chaves ML. (2004). Performance of chronotypes on memory tests during the morning and the evening shifts. Psychol. Rep. 95:75-85.

Hidalgo MP, Caumo W, Posser M, Coccaro SB, Camozzato AL, Chaves ML. (2009).

Relationship between depressive mood and chronotype in healthy subjects. Psychiatry Clin. Neurosci. 63:283-290.

Hogben AL, Ellis J, Archer SN, von Schantz, M. (2007). Conscientiousness is a predictor of diurnal preference. Chronobiol. Int. 24:1249-1254.

Horne JA, Östberg O. (1976). A self-assessment questionnaire to determine morningnesseveningness in human circadian systems. Int. J. Chronobiol. 4:97-110. 
Horne JA, Brass CG, Petitt AN. (1980). Circadian performance differences between morning and evening 'types'. Ergonomics 23:29-36.

Hornik J, Miniero G. (2009). Synchrony effects on customers' responses and behaviors. Int. J. Res. Mark. 26:34-40.

Hsu CY, Gau SS-F, Shang C-Y, Chiu Y-N, Lee M-B. (2012). Associations between chronotypes, psychopathology, and personality among incoming college students. Chronobiol. Int. 29:491-501.

Huang M-C, Ho C-W, Chen C-H, Liu S-H, Chen C-C, Leu SJ. (2010). Reduced expression of circadian clock genes in male alcoholic patients. Alcoholism Clin. Exp. Res. 34:18991904.

Intons-Peterson MJ, Rocchi P, West T. McLellan K, Hackney A. (1998). Aging, optimal testing times, and negative priming. J. Exp. Psychol. Learn. Mem. Cogn. 24:362-376.

Intons-Peterson MJ, Rocchi P, West T. McLellan K, Hackney A. (1999). Aging, testing at preferred or non preferred times (testing optimality), and false memory. J. Exp. Psychol. Learn. Mem. Cogn. 25:23-40.

Iskra-Golec I, Smith L. (2006). Ultradian and asymmetric rhythms of hemispheric processing speed. Chronobiol. Int. 23:1229-1239.

Jackson LA, Gerard DA. (1996). Diurnal types, the "big five" personality factors, and other personal characteristics. J. Soc. Behav. Person. 11:273-284.

Jamieson AO, Zammit GK, Rosenberg RS, Davis JR, Walsh JK. (2001). Zolpidem reduces the sleep disturbance of jet lag. Sleep Med. 2:423-430.

Jankowski S. (2012). Morningness/Eveningness and satisfaction with life in a Polish sample. Chronobiol. Int. 29:780-785.

Jenkins A, Archer SN, von Schantz M. (2005). Expansion during primate radiation of a variable number tandem repeat in the coding region of the circadian clock gene period3. J. Biol. Rhythms 20:470-472.

Johansson C, Willeit M, Smedh C, Ekholm J, Paunio T, Kieseppa T, Lichtermann D, N. PraschakRieder, A. Neumeister, L. Nilsson G, Kasper S, Peltonen L, Adolfsson R, Schalling M, Partonen T. (2003). Circadian clock-related polymorphisms in seasonal affective disorder and their relevance to diurnal preference. Neuropsychopharmacol. 28:734-739.

Jones KH, Ellis J, von Schantz M, Skene DJ, Dijk DJ, Archer SN. (2007). Age-related change in the association between a polymorphism in the PER3 gene and preferred timing of sleep and waking activities. J. Sleep Res. 16:12-16.

Juda M. (2010). The importance of chronotype in shift work research. Institute for Medical Psychology, Ludwigs-Maximilians-Universität, Munich, Unpublished doctoral thesis. 
Kaliterna, L., Vidacek, S., Prizmic, Z., \& Radosevic-Viadacek, B. (1995). Is tolerance to shiftwork predictable from individual difference measures. Work Stress 9:140-147.

Kanazawa S, Perina K. (2009). Why night owls are more intelligent. Pers. Ind. Diff. 47:685-690.

Katzenberg D, Young T, Finn L, Lin L, King DP, Takahashi JS, Mignot M. (1998). A CLOCK polymorphism associated with human diurnal preference. Sleep 21:569-576.

Kerkhof GA, Van Dongen HPA. (1996). Morning-type and evening-type individuals differ in the phase position of their endogenous circadian oscillator. Neurosci. Lett. 218:153-156.

Khaleque A. (1999). Sleep deficiency and quality of life of shift workers. Soc. Indic. Res. 46:181189.

Killgore WDS, Killgore DB. (2007). Morningness-eveningness correlates with verbal ability in women but not in men. Percept. Mot. Skills 104:335-338.

Kim S, Dueker GL, Hasher L, Goldstein D. (2002). Children's time of day preference: Age, gender, and ethnic differences. Pers. Ind. Diff. 33:1083-1090.

Kim SJ, Lee YJ, Kim H, Cho IH, Lee JY, Cho SJ. (2010). Age as a moderator of the association between depressive symptoms and morningness-eveningness. J. Psychosom. Res. 68:159164.

Kitamura S, Hida A, Watanabe MK, Enomoto M, Aritake-Okada S, Riguchi YM, Kamei Y, Mishima K. (2010). Evening preference is related to the incidence of depressive states independent of sleep-wake conditions. Chronobiol. Int. 27:1797-1812.

Kleitman N. (1963). Sleep and wakefulness. Chicago: University of Chicago Press.

Klerman EB, Dijk DJ (2008). Age-related reduction in the maximal capacity for sleep-implications for insomnia. Curr. Biol. 18:1118-1123.

Ko CH, Takahashi JS. (2006). Molecular components of the mammalian circadian clock. Hum. Mol. Genet. 15:R271-277.

Koskenvuo M, Hublin C, Partinen M, Heikkila K, Kaprio J. (2007). Heritability of diurnal type: a nationwide study of 8753 adult twin pairs. J. Sleep Res. 16:156-162.

Kripke DF. (1984). Critical interval hypotheses for depression. Chronobiol. Int. 1:73-80.

Kudielka BM, Federenko IS, Hellhammer DH, Wüst S. (2006). Morningness and eveningness:

The free cortisol rise after awakening in "early birds" and "night owls". Biol. Psychol. 72:141-146.

Kudielka BM, Bellingrath S, Hellhammer DH. (2007). Further support for higher salivary cortisol levels in "morning" compared to "evening" persons. J. Psychosom. Res. 62:595-596.

Laird DA. (1925). Relative performance of college students as conditioned by time of day on day week. J. Exp. Psychol. 3:50-63. 
Lavie P, Segal S. (1989). Twenty four hour structure of sleepiness in morning and evening person investigated by ultrashort sleep-wake paradigm. Sleep 21:522-528.

Lázár AS, Slak A, Lo JC-Y, Santhi N, von Schantz M, Archer SN, Groeger JA, Dijk DJ. (2012). Sleep, diurnal preference, health, and psychological well-being: A prospective singleallelic-variation study. Chronobiol. Int. 29:131-146.

Lawson EA, Miller KK, Blum JI, Meenaghan E, Misra M, Eddy KT, Herzog DB, Klibanski A. (2012). Leptin levels are associated with decreased depressive symptoms in women across the weight spectrum, independent of body fat. Clin. Endocrinol. 76:520-525.

Lee HM,Chen R, Kim H, Etchegaray JP, Weaver DR, Lee C. (2011). The period of the circadian oscillator is primarily determined by the balance between casein kinase 1 and protein phosphatase 1. Proc. Natl. Acad. Sci. U S A 108:16451-16456.

Lee KY, Song JY, Kim SH, Kim SC, Joo EJ, Ahn YM, Kim YS. (2010). Association between CLOCK $3111 \mathrm{~T} / \mathrm{C}$ and preferred circadian phase in Korean patients with bipolar disorder. Prog. Neuro-Psych. Biol. Psych.34:1196-1201.

Leger D, Guilleminault C, Defrance R, Domont A, Paillard M. (1999). Prevalence of sleep/wake disorders in persons with blindness. Clin. Sci. 97:193-199.

Lépine JP, Briley M. (2011). The increasing burden of depression. Neuropsychiatr. Dis. Treat. $7: 3-7$.

Levandovski R, Dantas G, Fernandes LC, Caumo W, Torres I, Roenneberg T, Hidalgo MP, Allebrandt KV. (2011). Depression scores associate with chronotype and social jetlag in a rural population. Chronobiol. Int. 28:771-778.

Lewy AJ, Lefler BJ, Emens JS, Bauer VK. (2006). The circadian basis of winter depression. Proc. Natl. Acad. Sci. 9:7414-7419.

Lewy AJ, Sack RL, Miller LS, Hoban TM. (1987). Antidepressant and circadian phase-shifting effects of light. Science 235:352-354.

Liu X, Uchiyama M, Shibui K, Kim K, Kudo Y, Tagaya M, Suzuki H, Ogawa M. (2000). Diurnal preferences, sleep habits, circadian sleep propensity and melatonin rhythm in healthy human subjects. Neuros. Lett. 280: 199-202.

Luyster FS, Strollo PJ, Zee PC, Walsh JK. (2012). Sleep: a health imperative. Sleep 35:727-734.

Magri F, Sarra S, Cinchetti W, Guazzoni V, Fioravanti M, Cravello L, Ferrari E. (2005). Qualitative and quantitative changes of melatonine levels in physiological and pathological aging and in centenarians. J. Pineal Res. 37:256-261.

Martin JS, Hébert M, Ledoux E, Gaudreault M, Laberge L. (2012). Relationhip of chronotype to sleep, ligth exposure, and work-realted fatigue in students workers. Chronobiol. Int. 29:295-304. 
Matchoock RL, Mordkoff JT. (2009). Chronotype and time of day influences on alerting, orienting, and executive components of attention. Exp. Brain. Res. 192:189-198.

May CP. (1999). Synchrony effects in cognition: the cost and the benefit. Psychon. Bull. Rev. $6: 142-147$.

May CP, Hasher L. (1998). Synchrony effects in inhibitory control thought and action. J. Exp. Psychol. Hum. Perc. Perf. 24:363-379.

McClung, C. A. (2007). Circadian rhythms, the mesolimbic dopaminergic circuit, and drug addiction. Sci. World J. 7(S2):194-202.

McClung CA, Sidiripoulo K, Vitaterna M, Takahashi JS. (2005). Regulation of dopaminergic transmission and cocaine reward by the Clock gene. Proc. Natl. Acad. Sci. 12: 9377-9381.

McLaughlin C, Bowman ML, Bradley CL, Mistlberger RE. (2008). A prospective study of seasonal variation in shift-work tolerance. Chronobiol. Int. 25:455-470.

Mecacci L, Rocchetti G. (1998). Morning and evening types: Stress-related personality aspects. Pers. Ind. Diff. 25:537-542.

Merikango I, Kronholm E, Peltonen M, Laatikainen T, Lahti T, Partonen T. (2012). Relation of chronotype to sleep complaints in the general Finnish population. Chronobiol. Int. 29:311317.

Minors D, Rabbitt PMA, Worthington H, Waterhouse J. (1989). Variation in meals and sleepactivity patterns in aged subjects; its relevance to circadian rhythm studies. Chronobiol. Int. 6:139-146.

Mishima K, Tozawa T, Satoh K, Saitoh H, Mishima Y. (2005). The 3111T/C polymorphism of hClock is associated with evening preference and delayed sleep timing in a Japanese population sample. Am. J. Med. Genet. B Neuropsychiatr. Genet. 133:101-104.

Mitchell PJ, Redman JR. (1993).The relationship between morningness-eveningness, personality and habitual caffeine consumption. Pers. Ind. Diff. 15:105-108.

Mongrain V, Carrier J, Dumont M (2005). Chronotype and sex effects on sleep architecture and quantitative sleep EEG in healthy young adults. Sleep 28:819-827.

Mongrain V, Carrier J, Dumont M. (2005). Circadian and homeostatic sleep regulation in morningness-eveningness. J. Sleep Res. 15:162-166.

Mongrain V, Carrier J, Dumont M (2006). Difference in sleep regulation between morning and evening circadian types as indexed by antero-posterior analyses of the sleep EEG. Eur. J. Neurosci. 23:497-504.

Mongrain V, Lavoie S, Selmaoui B, Paquet J, Dumont M. (2004). Phase relationship between sleep-wake cycle and underlying rhythms in morningness-eveningness. J. Biol. Rhythms 19:248-257. 
Mongrain V, Paquet J, Dumont M. (2006). Contribution of the photoperiod at birth to the association between season of birth and diurnal preference. Neurosc. Lett. 406 :113-116.

Monk TH, Buysse DJ, Potts JM, DeGrazia JM, Kupher DJ. (2004). Morningness-eveningness and lifestyle regularity. Chronobiol. Int. 21:435-443.

Monk TH, Kupher DJ. (2000). Circadian rhythms in healthy aging - Effects downstream from the pacemaker. Chronobiol. Int. 17:355-368.

Monk TH, Leng CV. (1986). Interaction between inter-individual and inter-task differences in the diurnal variations of human performance. Chronobiol. Int. 4:393-404.

Muro A, Gomà-i-Freixanet M, Adan A. (2009). Morningness-eveningness, sex, and the alternative five factor model of personality. Chronobiol. Int. 26:1235-1248.

Muro A, Gomà-i-Freixanet M, Adan A., Cladellas R. (2011). Circadian typology, age, and the Alternative Five-Factor Personality model in an adult women sample. Chronobiol. Int. 28:690-696.

Nagane M, Suge R, Watanabe S-I. (2011). Relationship between psychosomatic complaints and circadian rhythm irregularity assessed by salivary levels of melatonin and growth hormone. J. Circadian Rhythms 9:9, http://www.jcircadianrhythms.com/content/9/1/9

Natale V, Adan A. (1999). Season of birth modulates the morningness-eveningness preference. Neurosc. Lett. 274:139-141.

Natale V, Adan A, Chotai J. (2002). Further results on the association between morningnessevenigness preference and the season of birth in human adults. Neuropsychobiol. 46:209214.

Natale V, Adan A, Fabbri M. (2009). Season of birth, gender and social-cultural effects on sleep timing preferences in humans. Sleep 32:423-426.

Natale V, Alzani A, Cicogna PC. (2003). Cognitive efficiency and circadian typology: a diurnal study. Pers. Ind. Diff. 35:1089-1105.

Natale V, Cicogna PC. (1996). Circadian regulation of subjective alertness in morning and evening type. Pers. Ind. Diff. 20:491-497.

Natale V, Di Milia L. (2011). Season of birth and morningness: comparison between the northern and southern hemispheres. Chronobiol. Int. 28:727-730.

Natale V, Esposito MJ, Martoni M, Fabbri M. (2006). Validity of the reduced version of the Morningness-Eveningness Questionnaire. Sleep Biol. Rhythms 4:72-74.

Natale V, Lorenzetti R. (1997). Influences of morningness-eveningness and time of day on narrative comprehension. Pers. Ind. Diff. 23:685-690.

Natvik S, Bjorvatn B, Moen BE, Mageroy N, Siversten B, Pallesen S. (2011). Personality factors related to shift work tolerance in two- and three-shift workers. App. Ergo. 42:719-724. 
Negriff S, Dorn LD. (2009). Morningness/Eveningness and menstrual symptoms in adolescent females. J. Psychosom. Res. 67:169-172.

Nielsen T. (2010). Nightmares associated with the eveningness chronotype. J. Biol. Rhythms 25:53-62.

Oginska H, Farowicz M, Golonka K, Marek T, Mojsa-Kaja J, Tucholska K. (2010). Chronotype, sleep loss, and diurnal pattern of salivary cortisol in a simulated daylong driving. Chronobiol. Int. 27:959-974.

Ong JC, Huang JS, Kuo TF, Manber R. (2007). Characteristics of insomniacs with self-reported morning and evening chronotypes. J. Clin. Sleep Med. 15:289-294.

O'Reardon JP, Ringel BL, Dinges DF, Allison KC, Rogers NL, Martino NS, Stunkard AJ. (2004).Circadian eating and sleeping patterns in the night eating syndrome. Obesity Res. 12:1789-1796.

Osland TM, Bjorvatn B, Steen VM, Pallesen S. (2011). Association study of a variable-number tandem repeat polymorphism in the clock gene PERIOD3 and chronotype in Norwegian university students. Chronobiol. Int. 28:764-770.

Ottoni GL, Antoniolli E, Lara DR. (2012). Circadian preference is associated with emotional and affective temperaments. Chronobiol. Int. 29:786-793.

Paine S-J, Gander PH, Travier N. (2006). The epidemiology of morningness/eveningness: Influence of age, gender, ethnicity, and socioeconomic factors in adults (30-49 years). $J$. Biol. Rhythms 21:68-76.

Park YM, Matzumoto K, Seo YJ, Kang MJ, Nagashima H. (2002). Effects of age and gender on sleep habits and sleep trouble for aged people. Biol. Rhythms Res. 33:39-51.

Pedrazzoli M, Louzada FM, Pereira DS, Benedito-Silva AA, Lopez AR, Martynhak BJ, Korczak AL, Koike Bdel V, Barbosa AA, D'Almeida V, Tufik S. (2007). Clock polymorphisms and circadian rhythms phenotypes in a sample of the Brazilian population. Chronobiol. Int. 24:1-8.

Peiser B. (2009). Seasonal affective disorder and exercise treatment: a review. Biol. Rhythm Res. 40:85-97.

Pereira DS, Tufik S, Louzada FM, Benedito-Silva AA, Lopez AR, Lemos NA, Korczak AL, D'Almeida V, Pedrazzoli M. (2005). Association of the length polymorphism in the human Per3 gene with the delayed sleep-phase syndrome: does latitude have an influence upon it? Sleep 28:29-32.

Perreau-Lenz S, Spanagel R. (2008). The effects of drugs of abuse on clock genes. Drug News Pers. 21:211-217. 
Perreau-Lenz S, Zghoul T, Rodríguez de Fonseca F, Spanagel R, Bilbao A. (2009). Circadian regulation of central ethanol sensitivity by the mPer2 gene. Addiction Biol. 14:253-259.

Petros TV, Beckwith BE, Anderson M. (1990). Individual differences in the effects of time of day and passage difficulty on prose memory in adults. Brit. J. Psychol. 81:63-72.

Petru R, Wittmann M, Nowak, D, Birkholz B, Angerer P. (2005). Effects of working permanent night shifts and two shifts on cognitive and psychomotor performance. Int. Arch. Occupt. Environ. Health 78:109-116.

Pornpitakpan C. (1998). Psychometric properties of the Composite Scale of Morningness: A shortened version. Pers. Ind. Diff. 25:699-709.

Prat G, Adan A. (2011). Influence of circadian typology on drug consume, hazardous alcohol use and hangover symptoms. Chronobiol. Int. 28:248-257.

Randler C. (2008a). Morningness-eveningness comparison in adolescents from different countries around the world. Chronobiol. Int. 25:1017-1028.

Randler C. (2008b). Morningness-eveningness and satisfaction with life. Soc. Indic. Res. 86:297302.

Randler C. (2008c). Morningness-Eveningness, sleep-wake variables and Big Five Personality Factors. Pers. Ind. Diff. 45:191-196.

Randler C. (2009a). Validation of the full and reduced Composite Scale of Morningness. Biol. Rhythm Res. 40:413-423.

Randler C. (2009b). Proactive people are morning people. J. Appl. Soc. Psychol. 39:2787-2797.

Randler C. (2011). Age and gender differences in morningness-eveningness during adolescence. J. Genetic Psychol. 172:302-308.

Randler C, Bilger S, Díaz-Morales JF. (2009). Associations among sleep, chronotype, parental monitoring, and pubertal development among German adolescents. J. Psychol. 143:509520.

Randler C, Ebenhöh N, Fischer A, Höchel S, Schroff C, Stoll JC, Vollmer C. (2012). Chronotype but not sleep length is related to salivary testosterone in young adult men. Psychoneuroendocrinology dx.doi.org/10.1016/j.psyneuen.2012.02.008 (in press)

Randler C, Frech D. (2006). Correlation between morningness-eveningness and final school leaving exams. Biol. Rhythm Res. 37:233-239.

Randler C, Saliger L. (2011). Relationship between morningness-eveningness and temperament and character dimensions in adolescents. Pers. Ind. Diff. 50:148-152.

Reinberg A, Touitou Y, Lewy H, Mechkouri M. (2010). Habitual moderate alcohol consumption desynchronizes circadian physiologic rhythms and affects reaction-time performance. Chronobiol. Int. 27:1930-1942. 
Roberts RD, Kyllonen PC. (1999). Morningness-eveningness and intelligence: early to bed, early to rise will likely make you anything but wise! Pers. Ind. Diff. 27:1123-1133.

Robilliard D, Archer SN, Arendt J, Lockley SW, Hack LM, English J, Leger D, Smits MG, Williams A, Skene DJ, von Schantz M (2002). The 3111Clock gene polymorphism is not associated with sleep and circadian rhythmicity in phenotypically characterized human subjects. J. Sleep Res. 11:305-312.

Roenneberg T, Allebrandt KV, Merrow M, Vetter C. (2012). Social jetlag and obesity. Curr. Biol. 22: 939-943.

Roenneberg T, Daan S, Merrow M. (2003). The art of entrainment. J. Biol. Rhythms 18:183-194.

Roenneberg T, Kuehnle T, Juda M, Kantermann T, Allebrandt K, Gordijn M, Merrow M. (2007). Epidemiology of the human circadian clock. Sleep Med. Rev. 11:429-438.

Roenneberg T, Kuehnle T, Pramstaller P P, Ricken J, Havel M, Guth A, Merrow M. (2004). A marker for the end of adolescence. Curr. Biol. 14:R1038-R1039.

Rosenthal NE, Sack DA, Gillin JC, Lewy AJ, Goodwin FK, Davenport Y, Mueller PS, Newsome DA, Wehr TA. (1984). Seasonal affective disorder. A description of the syndrome and preliminary findings with light therapy. Arch. Gen. Psychiatry 41:72-80.

Rosenwasser AM. (2009). Functional neuroanatomy of sleep and circadian rhythms. Brain Res. Rev. 61:281-306.

Rosenwasser, A.M. (2010). Circadian clock genes: non-circadian roles in sleep, addiction, and psychiatric disorders? Neurosc. Biobehav. Rev. 34:1249-1255.

Rowe G, Hasher L, Turcotte J. (2009). Age and synchronicy effects in visuospatial working memory. Q. J. Exp. Psychol. 62:1873-1880.

Rupp TL, Acebo C, Carskadon MA. (2007). Evening alcohol suppresses salivary melatonin in young adults. Chronobiol. Int. 24:463-470.

Russo PM, Bruni O, Lucidi F, Ferri R, Violani C. (2007). Sleep habits and circadian preference in Italian children and adolescents. J. Sleep Res. 16:163-169.

Sack RL, Auckley D, Auger RR, Carskadon MA, Wright Jr KP, Vitiello MV, Zhdanova IV.

(2007). Circadian rhythm sleep disorders: Part I, basic principles, shift work and jet lag disorders. Sleep 30:1460-1483.

Saksvik I, Bjorvatn B, Hetland H, Sandal GM, Pallesen S. (2011). Individual differences in tolerance to shift work - a systematic review. Sleep Med. Rev. 15:221-235.

Saksvik I. (2012). Individual, situational, and lifestyle factors related to shift work tolerance among nurses who are new to - and experienced in night work. J. Adv. Nurs. (in press)

Sand P, Kleinschitz M, Vogel P, Kavvadis D, Schreier P, Riederer P. (2001). Naturally occurring benzodiazepines may codetermine chronotypes. J. Neural. Transm. 108:747-753. 
Sarmàny I. (1984). Interacting features of cognitive style (field dependence-independence) and operator's simulated work during a 24-hour cycle - II: morning and evening type. Studia Psychol. 26:323-330.

Schmidt C, Peigneux P, Leclercq Y, Sterpenich V, Vandewalle G, Phillips C, Berthomier P, Berthomier C, Tinguely G, Gais S, Schabus M, Desseilles M, Dang-Vu T, Salmon E, Degueldre C, Balteau E, Luxen A, Cajochen C, Maquet P, Collette F. (2012). Circadian preference modulates the neural substrate of conflict processing across the day. PLoS One 7: e29658. doi:10.137 (in press)

Schneider ML, Vasconcellos DC, Dantas G, Levandovski R, Caumo W, Allebrandt KV, Doring M,Hidalgo MP. (2011). Morningness-eveningness, use of stimulants, and minor psychiatric disorders among undergraduate students. Int $J$ Psychol. 1:18-23.

Schubert E, Randler C. (2008). Association between chronotype and the constructs of the ThreeFactor-Eating-Questionnaire. Appetite 51:501-505.

Schwartz SH. (2003). A proposal for measuring value orientations across nations. Chapter 7. Questionnaire Development Package of the European Social Survey. Retrieved from http://www.europeansocialsurvey.org/index.php?option=com_docman\&task=doc_view\& gid $=126 \&$ Itemid $=80$

Selvi Y, Aydin A, Atli A, Boysan M, Selvi F, Besiroglu L. (2011). Chronotype differences in suicidal behavior and impulsivity among suicide attempters. Chronobiol. Int. 28:170-175.

Selvi Y, Aydin A, Boysan M, Atli A, Agargun MY, Besiroglu L. (2010).Associations between chronotype, sleep quality, suicidality, and depressive symptoms in patients with major depression and healthy controls. Chronobiol. Int. 27:1813-1828.

Seo Y-J, Matsumoto K, Park Y-M, Shinkoda H, Noh T-J. (2000). The relationship between sleep and shift system, age and chronotype in shift workers. Biol. Rhythm Res. 31:559-579.

Serretti A, Gaspar-Barba E, Calati R, Cruz-Fuentes CS, Gomez-Sanchez A, Perez-Molina A, De Ronchi D. (2010). 3111T/C clock gene polymorphism is not associated with sleep disturbances in untreated depressed patients. Chronobiol. Int. 27:265-277.

Shub Y, Ashkenazi IE, Reinberg A. (1997). Differences between left- and right-hand reaction time rhythms: indications of shift in strategies of human brain activity. Cog. Brain Res. 6:141-146.

Smith AP. (1992). Time of day and performance. In Handbook of human performance. Vol. 3. New York: Academic Press. pp. 217-235.

Smith CS, Reilly C, Midkiff K. (1989). Evaluation of three circadian rhythm questionnaires with suggestions for an improved measure of morningness. J. Appl. Psych.74:728-738. 
Smith CS, Robie C, Folkard S, Barton J, Macdonald I, Smith L, Spelten E, Totterdell P, Costa G. (1999). A process model of shiftwork and health. J. Occup. Health Psych. 4:207-218.

Smith CS, Folkard S, Schmieder RA, Parra LF, Spelten E, Almirall H, Sahu S, Periz L, Tisak J. (2002). Investigation of morning-evening orientation in six countries using the Preferences Scale. Pers. Ind. Diff. 32:949-968.

Song J, Stough C. (2000). The relationship between morningness-eveningness, time of day, speed of information processing, and intelligence. Pers. Ind. Diff. 29:1179-1190.

Soreca I, Fagiolini A, Frank E, Goodpaster BH, Kupfer DJ. (2009). Chronotype and body composition in bipolar disorder. Chronobiol. Int. 26:780-788.

Soria V, Urretavizcaya M. (2009). Circadian rhythms and depression. Actas Esp. Psiquiatr. $37: 222-232$.

Springer SP, Deutsch G. (1997). Left brain, right brain. San Francisco, CA: Freeman.

Sterberg RJ, Zhang LF. (2001). Perspectives on thinking, learning, and cognitive styles. Mahawah: LEA.

Taillard J, Philip P, Bioulac B. (1999). Morningness/eveningness and the need for sleep. J. Sleep Res. 8:291-295.

Taillard J, Philip P, Chastang J-F, Bioulac B. (2004). Validation of Horne and Östberg Morningness-Eveningness questionnaire in a middle-aged population of French workers. J. Biol. Rhythms 19:76-86.

Taillard J, Philip P, Claustrat B, Capelli A, Coste O, Chaumet G, Sagaspe P. (2011). Time course of neurobehavioral alertness during extended wakefulness in morning- and evening-type healthy sleepers. Chronobiol. Int. 28:520-527.

Takao M, Kurach T, Kato H. (2009). Photoperiod at birth does not modulate the diurnal preference in Asian population. Chronobiol. Int. 26:1470-1477.

Tankova I, Adan A, Buela-Casal G. (1994). Circadian typology and individual differences: A review. Pers. Ind. Diff. 16:671-684.

Taylor DJ, Clay KC, Bramoweth AD, Sethi K, Roane BM. (2011). Circadian phase preference in college students: relationship with psychological functioning and academics. Chronobiol. Int. 28:541-547.

Terman JS, Terman M, Lo ES, and Cooper TB. (2001). Circadian time of morning light administration and therapeutic response in winter depression. Arch. Gen. Psychiat. Res. 58:69-75.

Toh KL, Jones CR, He Y, Eide EJ, Hinz WA, Virshup DM, Ptacek LJ, Fu YH. (2001). An hPer2 phosphorylation site mutation in familial advanced sleep phase syndrome. Science 291:1040-1043. 
Tzischinsky O, Shochat T. (2011). Eveningness, sleep patterns, daytime functioning, and quality of life in Israeli adolescents. Chronobiol. Int. 28:338-343.

Tonetti L, Fabbri M, Martoni M, Natale V. (2011). Season of birth and sleep-timing preferences in adolescents. Chronobiol. Int. 28:536-540.

Tonetti L, Fabbri M, Natale V. (2008). Sex differences in sleep-time preference and sleep need: a cross-sectional survey among Italian pre-adolescent, adolescent and adults. Chronobiol. Int. 25:745-759.

Tonetti L, Fabbri M, Natale V. (2009). Relationship between circadian typology and big five personality domains. Chronobiol. Int. 26:337-347.

Torrance EP, McCarthy B, Kolesinski MT. (1988). Style of Learning and Thinking. Bensenville, IL: Scholastic Testing Service.

Torsvall L, Akerstedt T. (1980). A diurnal type scale. Construction, consistency and validation in shift work. Scand. J. Work Enviro. Health 6:283-290.

Tsaousis I. (2010) Circadian preferences and personality traits: a meta-analysis. Eur. J. Pers. 24:356-373.

Urbán R, Magyaródi T, Rigó A. (2011). Morningness-Eveningness, chronotypes and healthimpairing behaviors in adolescents. Chronobiol. Int. 28:238-247.

Uz T, Ahmed R, Akhisaroglu M, Kurtunku M, Imbese M, Dirim Arslam A, Manev H. (2005). Effect of fluoxetine and cocaine in the expression of clock genes in the mousse hippocampus and striatum. Neuroscience 134:1309-1316.

Valdez P, Reilly T, Waterhouse J. (2008). Rhythms of mental performance. Mind Brain Educ. 2:7-16.

Vanin S, Bhutani S, Montelli S, Menegazzi P, Green EW, Pegoraro M, Sandrelli F, Costa R, Kyriacou CP. (2012). Unexpected features of Drosophila circadian behavioural rhythms under natural conditions. Nature (in press)

Vela-Bueno A, Olavarrieta-Bernardino S, Fernandez-Mendoza J, Vgontzas A, Bixler E, de la Cruz Troca JJ. (2010). Circadian profile and locus of control in shiftworking aircraft maintenance technicians: Differences on adaptation. 20th Congress of the European Sleep Research Society Lisbon, Portugal 14.09.2010 - 18.09.2010.

Viola AU, Archer SN, James LM, Groeger JA, Lo JC, Skene DJ, von Schantz M, Dijk DJ(2007). PER3 polymorphism predicts sleep structure and waking performance. Curr. Biol. 17:613618.

Viola AU, Chellappa SL, Archer SN, Pugin F, Gotz T, Dijk DJ, Cajochen C. (2011). Interindividual differences in circadian rhythmicity and sleep homeostasis in older people: effect of a PER3 polymorphism. Neurobiol. Aging 33:1010.e17-1010.e27. 
Vollmer C, Randler C. (2012). Circadian preferences and personality values: Morning types prefer social values, evening types prefer individual values. Pers. Ind. Diff. 52:738-743.

Vollmer C, Michel U, Randler C. (2012). Outdoor ligth at night (LAN) is correlated with eveningness in adolescents. Chronobiol. Int. 29:502-508.

Waterhouse J, Edwards B, Nevill A, Carvalho S, Atkinson G, Buckley P, Reilly T. (2002). Identifying some determinants of "jet-lag" and its symptoms: a study of athlethes and other travellers. Brit. J. Sports Med. 36:54-60.

Waterhouse J, Reilly T, Atkinson G, Edwards B. (2007). Jet lag: Trends and coping strategies. Lancet 369:1117-1129.

Wehr TA, Wirz-Justice A, Goodwin FK, Duncan W, Gillin JC. (1979). Phase advance of the circadian sleep-wake cycle as an antidepressant. Science 206:710-713.

Wieth MB, Zacks RT. (2011). Time of day effects on problem solving: when the non-optimal is optimal. Think Reas. 17:387-401.

Wirz-Justice A, Benedetti F, Berger M, Lam RW, Martiny K, Terman M, Wu JC. (2005). Chronotherapeutics (light and wake therapy) in affective disorders. Psychol Med. 35:939944.

Willis TA, O'Connor DB, Smith L. (2008). Investigating effort-reward imbalance and workfamily conflict in relation to morningness-eveningness and shift work. Work Stress 22:125-137.

Wittmann M, Paulus M, Roenneberg T. (2006). Social jetlag: misalignment of biological and social time. Subs. Use Misuse 23:497-509.

Wu Y-H, Swaab DF. (2005). The human pineal gland and melatonin in aging and Alzheimer's disease. J. Pineal Res. 38:145-152.

Wulff K, Gatti S, Wettstein JG, Foster RG. (2010). Sleep and circadian rhythm disruption in psychiatric and neurodegenerative disease. Nat. Rev. Neurosci. 11:589-599.

Xu Y, Padiath QS, Shapiro RE, Jones CR, Wu SC, Saigoh N, Saigoh K, Ptacek LJ, Fu YH. (2005). Functional consequences of a CKIdelta mutation causing familial advanced sleep phase syndrome. Nature 434:640-644.

Yang L, Hasher L, Wilson DE. (2007). Synchrony effects in automatic and controlled retrieval. Psychon. Bull. Rev. 14:51-56.

Zickar MJ, Russell SS, Smith CS, Bohlé P, Tilley AJ. (2002). Evaluating two morningness scales with item response theory. Pers. Ind. Diff. 33:11-24.

Zimmermann LK. (2011). Chronotype and the transition to college life. Chronobiol. Int. 28:904910. 
Zuckerman M. (2002). Zuckerman-Kuhlman Personality Questionnaire (ZKPQ): An alternative fivefactorial model. In: De Raad B, Perugini M. (Ed). Big five assessment. Seattle, Wash: Hogrefe \& Huber Publishers, pp. 377-396.

Zuckerman M, Cloninger CR. (1996). Relationships between Cloninger's, Zuckerman's and Eysenck's dimensions of personality. Pers. Ind. Diff. 21:283-285.

Zuckerman M, Kuhlman DM, Joireman J, Teta P, Kraft M. (1993) A comparison of three structural models for personality: The Big Three, the Big Five, and the Alternative Five. $J$. Pers. Soc. Psychol. 65:757-768. 
FIGURE 1- Molecular, physiological and clinical levels involved in Circadian Typology.

At the molecular level, a set of core circadian clock genes is involved with determining circadian typology (A).

At the physiological level, light reception entrains the central circadian clock in the suprachiasmatic nucleus, which drives circadian outputs such as melatonin synthesis (B). The neurotransmitters involved in the etiology of mental disorders participate directly in the synthesis of melatonin (C). Factors such as stress trigger the induction of tryptophan pirolase, capable of destroying tryptophan before it reaches the pineal gland (D). Tryptophan diminish the production of Leptin, which is involved in food intake, weight gain, and increases risk of cardiovascular diseases. Leptin also increases the level of dopamine (E).

Molecular and physiological pathways interact to define a behavioral circadian typology phenotype that can be measure by self-assessment scales and/or several biological outputs (F). 